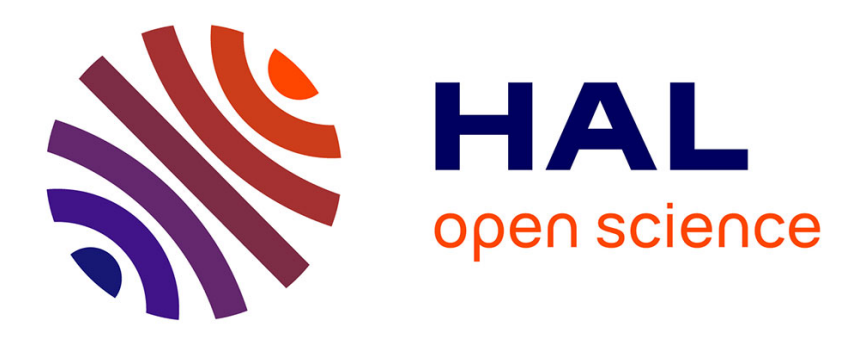

\title{
From denominal derivation to Incorporation
}

Guillaume Jacques

\section{To cite this version:}

Guillaume Jacques. From denominal derivation to Incorporation. Lingua, 2012, 122, pp.1207-1231. halshs-00821301

\section{HAL Id: halshs-00821301 https://shs.hal.science/halshs-00821301}

Submitted on 8 May 2013

HAL is a multi-disciplinary open access archive for the deposit and dissemination of scientific research documents, whether they are published or not. The documents may come from teaching and research institutions in France or abroad, or from public or private research centers.
L'archive ouverte pluridisciplinaire HAL, est destinée au dépôt et à la diffusion de documents scientifiques de niveau recherche, publiés ou non, émanant des établissements d'enseignement et de recherche français ou étrangers, des laboratoires publics ou privés. 


\title{
From denominal derivation to incorporation ${ }^{1}$
}

\author{
Guillaume JACQUES \\ CNRS-INALCO-EHESS, CRLAO
}

\begin{abstract}
This article investigates the synchronic status and diachronic origin of an incorporation-like construction in Japhug, a polysynthetic SinoTibetan language of Eastern Tibet. This construction constitutes the intermediate stage on a path of development from denominal derivation to incorporation, the opposite of the usual path of development from incorporation to denominal derivation.

Additionally, this article shows that similar phenomena exist in other languages, and that coalescence between noun and verb is not the only attested diachronic origin of incorporating verbs.
\end{abstract}

Keywords: Rgyalrong; Japhug; incorporation; denominal verbs; composition; grammaticalization; English; German

\section{Introduction}

This article deals with the diachronic origin of incorporation and its relationship to denominal derivation, drawing examples from Japhug Rgyalrong, a polysynthetic language belonging to the Sino-Tibetan family.

Most studies dealing with incorporation in a diachronic perspective (for instance Mattissen 2006, Haugen 2008, Mithun 2009) discuss the development of new constructions (denominal derivation, manner or classifier morphemes etc) out of incorporation, rather than the origin of incorporation itself.

Mithun (1984: 872) suggests that the genesis of incorporation is the result of the coalescence of nouns (especially indefinite direct object) with the

\footnotetext{
${ }^{1}$ I would like to thank Anton Antonov, Denis Creissels, Romain Garnier, Antoine Guillaume, Gong Xun, Nathan Hill, Aimée Lahaussois, Lai Yunfan, Johanna Mattisen, Alexis Michaud, Thomas Pellard, Wu Tong, Mark Van de Velde and three anonymous reviewers for useful comments on this article. This research was sponsored by the Agence Nationale de la Recherche (France) as part of the research project "What defines Qiang-ness? Towards a phylogenetic assessment of the Southern Qiangic languages of Muli" (acronym PASQi) (ANR-07-JCJC-0063) and by the Labex EFL (Empirical Foundations of Linguistics, GD1, Typology and annotation of information structure and grammatical relations). Glosses follow the Leipzig glossing rules, except for the following: CISL cislocative, CONST constative, COORD coordination, EMPH emphatic particle, GENR generic, IDEO ideophone, INV inverse, NEU neutral, STAT stative.
} 
verb, and this observation is certainly valid for most incorporating languages.

In languages where the incorporated noun is always the outermost element of the verb, the explanation of incorporation in terms of coalescence is obvious and hardly deserves a justification.

The present study will however show that incorporation does not always derive from coalescence of noun and verb, but originates in some cases from denominal derivation. This pathway of development is exemplified in Japhug, where incorporation is a relatively recent phenomenon, but traces of it can be found in other languages.

This article is divided into five parts. First, we provide a definition of incorporation to distinguish it from related but distinct phenomena.

Second, we provide a detailed description of an incorporation-like construction in Japhug.

Third, we describe denominal derivation in Japhug and its similarities with the incorporation-like construction.

Fourth, we analyse the development pathway that led to the creation of the incorporation-like construction in Japhug, and evaluate whether this construction represents true incorporation.

Fifth, we propose to distinguish two types of incorporation in crosslinguistic perspective, direct (the classical type) and indirect (the type observed in Japhug), and show the existence of indirect incorporation in Germanic languages.

\section{Incorporation and its relationship to other morphological phe- nomena}

The term "incorporation" is generally used, according to Mithun (1984: 848)'s definition, to designate a "particular type of compounding in which a $\mathrm{V}$ and N combine to form a new V". Such a definition allows for broad or narrow interpretations, depending on one's understanding of "compounding", "verb" and "noun". Since this article discusses the diachrony of incorporation and its relationship to related but distinct constructions, it is preferable to opt for a more restrictive definition, following Sapir (1911), Gerdts (1998) and Mattissen (2003: 169).

We define incorporation as the compounding of a nominal root with a verbal root into a verb, on the conditions that 1) both the nominal and the verbal stems in question exist as independent words (even with morphophonological changes); 2) the resulting incorporational construction can occur in finite forms; 3) the resulting incorporational construction constitutes both a phonological and a morphological word; 4) verbs and nouns are clearly distinct parts of speech in the language in question (without excluding cases of noun / verb homophony). 
This definition can distinguish genuine incorporation from three processes that some authors have analyzed as incorporation: denominal derivation, noun stripping and lexical affixes.

First, denominal derivation and incorporation are related concepts, and the term "incorporation" is sometimes used to include both verbs deriving from nouns and compound verbs built from a nominal and a verbal root (see in particular the debate between Mithun 1984, Mithun 1986 and Sadock 1980 and Sadock 1986). As Sadock and other authors such as Haugen (2008) have argued, in some language families, especially Eskaleut and Uto-Aztecan, denominal derivation and incorporation present systematic parallelism, and denominal verbs can even be analyzed as a sub-class of incorporating verbs, one in which the verb root "requires incorporation of a nominal root or stem for morphophonological reasons" (Haugen 2008: 120). Mithun (2009: 13), discussing Eskaleut data, objects that even though denominal verbs in these languages are historically derived from incorporating verbs, the fact that the verb root cannot appear independently precludes analysing it as incorporation synchronically. Her data include a few examples in which the same root appears both as an independent verbal root and as a suffix, such as Central Alaskan Yupik atub- "to use, to sing, to wear" (Fortescue et al. 2010: 57) and the corresponding suffix (postbase) -tus- "eat X", less commonly "use, wear" (Fortescue et al. 2010: 473). According to our definition of incorporation, the Eskaleut denominal suffixes that have no verbal equivalent should not be analyzed as incorporation, but examples of the suffix - tub-cited by Mithun should, even though the morphological shape of the suffix is not entirely predictable from the base verb and some semantic differences can be discerned.

We propose the following definition for denominal verb derivation: a morphological process that derives a verb out of a noun either by 1) addition of an affix and/or non-concatenative morphology 2) zero-derivation. In cases where the affix is etymologically related to a free verb like the postbase -tub- "eat X" in Yupik mentioned above, it is preferable to analyse the construction as incorporation rather than denominal derivation.

Second, some authors consider noun stripping to be a form of incorporation: Mithun (1984: 849-854) analyses as noun-stripping cases where a noun is juxtaposed to a verb, without any element occurring in between, and loses its syntactic status as an argument of the sentence while remaining a phonologically independent word. Our definition of incorporation excludes such cases, though as pointed out by Mithun (1984: 872), incorporation might originate from noun stripping by progressive coalescence of a nominal and a verbal root.

Third, in Northwest North American languages such as Wakashan and Salish, lexical affixes with meanings corresponding to nouns or adverbs in European languages can be attached to the verb; these lexical affixes strongly resemble incorporation at least in function. However, these affixes generally 
have no synchronic relationship with free lexical elements, and even when they do, the fact that Salishan and Wakashan languages lack a strong nounverb distinction makes it difficult to determine with confidence whether a particular compound is a verb-verb or a noun-verb compound. However, the situation is different in the case of Algonquian, a family with a very strong verb-noun distinction. In Algonquian languages, the so-called MEDIAL stems (Goddard 1990) are (generally nominal) lexical affixes, some of which have a clear relationship with the corresponding free noun. Incorporating verbs in Algonquian follow the general template:

(1) INITIAL + MEDIAL + FINAL

Only INITIAL roots can appear on their own; they can be either verbal or nominal. The FINAL roots are mainly derivational morphemes, in particular voice and valency markers.

Consider the following examples of incorporating verbs in Ojibwe (data from Nichols \& Nyholm 1995); the MEDIAL is indicated in bold. All of these examples share the final $-\boldsymbol{e}$ of intransitive animate verbs:

(2) ikwe- "woman" > miigaad-ikwew-e "beat (one's) wife" (compare miigaadi"fight each other"), Nichols \& Nyholm 1995[64]

inini- "man" > nawad-iniw-e "grab people" (compare nawadin- "grab s.o."), Nichols \& Nyholm 1995[93]

zhiishiib- "duck" > nandaw-ishib-e "hunt ducks", Nichols \& Nyholm 1995[92]

anim- "dog" > nandaw-isimw-e "look for horses", Nichols \& Nyholm $1995[92]$

The relationship between the free noun (the INITIAL root) and the MEDIAL is in some cases quite transparent, as in ikwe- > -(i)kwew- "woman" (the final etymological $-w$ shows up in the plural ikwewag "women"). In most cases, however, the MEDIAL is not predictable (inini- $>-$ iniw- "man" and zhiishiib- > (i)shib "duck") or even entirely obscure synchronically anim- > -(i)simw- "dog, horse". 2

However, despite the unpredictable morphophonological processes taking place when deriving a medial from the free root, these examples constitute incorporation according to our definition. The case of Wakashan and Salis-

\footnotetext{
${ }^{2}$ The bare Initial anim- does not normally occur in Ojibwe; the common noun for "dog", animosh is a diminutive of an earlier *anim < *atemwa "dog" which fell out of use in Ojibwe but whose cognates still exist and other Algonquian languages. The MEDIAL -(i)

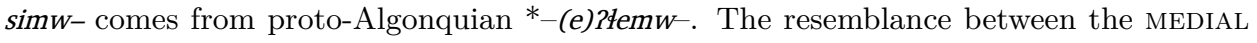
and the INITIAL is manifest in the proto-language, but no longer apparent in modern Ojibwe.
} 
han is more complex and will not be discussed in this article (see Gerdts 2003 and also Gerdts \& Hukari 2008 concerning the Salish language Halkomelem).

Aside from the cases discussed above, our definition excludes cases such as English "go berry-picking" which can occur with participles but not finite forms, at least not in the standard language. ${ }^{3}$

Any definition is at least in part arbitrary, and we do not wish to imply that authors such as Haugen (2008) or Baker (2009) were "wrong" in designating as incorporation phenomena which we would call otherwise. The only important question is whether a particular comparative concept is clear or ambiguous, and whether it is useful for analysing data.

The survey of the literature above shows that previous authors have proposed two paths of development related to incorporation.

First, the development of denominal derivation from incorporation, when an incorporating verb ceases to be usable without an incorporated noun:

\section{(3) INCORPORATION > DENOMINAL DERIVATION}

Second, the development of incorporation from noun stripping, by coalescence of the noun and the verb stems into one phonological word:

\section{(4) NOUN-VERB COALESCENCE > INCORPORATION}

The following will show that (4) is not the only path of development leading to the creation of incorporation.

\section{An incorporation-like construction in Japhug}

Incorporation is a rather unusual process among languages of the SinoTibetan family. Mithun (1984: 853) has argued, quoting data from Matisoff (1973: 309), that some constructions in the Lolo-Burmese language Lahu could be analysed as incorporation, but as mentioned in section 2, we exclude noun-stripping from our definition of incorporation.

In the morphologically richer languages of the Sino-Tibetan family, there is evidence for the existence of incorporation, especially in Kiranti (see for instance Schackow 2008: 92 concerning Puma), but also in the ancient language Tangut (Jacques 2011).

Japhug, a morphologically complex language belonging to another subgroup of Sino-Tibetan (Rgyalrong), presents a peculiar incorporation-like construction which will be the focus of this article. This construction (henceforth ILC) resembles incorporation superficially and was analysed as such in previous publications such as Jacques (2004) and Jacques (2012b). At the same time, it presents affinities with denominal derivation (as will be shown

\footnotetext{
${ }^{3} \mathrm{~A}$ search on the internet however reveals that sentences such as "he berry-picks it" are possible in some colloquial varieties of English: This constitutes incorporation.
} 
in section 5), and we defer discussion of its exact status until sections 5 and 6 .

In this section we first give a short presentation of the Japhug language. Second, we provide a general overview of Japhug morphosyntax. Third, we present all examples of ILC verbs in Japhug: this construction is of limited productivity, so that an exhaustive list can be included in this article. Fourth, we describe some morphological and syntactic properties of the ILC.

\subsection{The Japhug language}

Japhug (Chinese 茶堡 Chabao) is an endangered Sino-Tibetan language spoken by less than 10000 speakers in Western Sichuan, China. It belongs to the Rgyalrong subgroup of Sino-Tibetan (as defined by Sun 2000). Alongside Japhug, three other languages are found in the Rgyalrong group: Situ (or Eastern Rgyalrong), Tshobdun (Chinese 草登 Caodeng) and Zbu (Chinese Ribu 日部, also called Showu).

The following map presents the Rgyalrong-speaking area in shaded grey, in which the Japhug-area appears as a black dot:

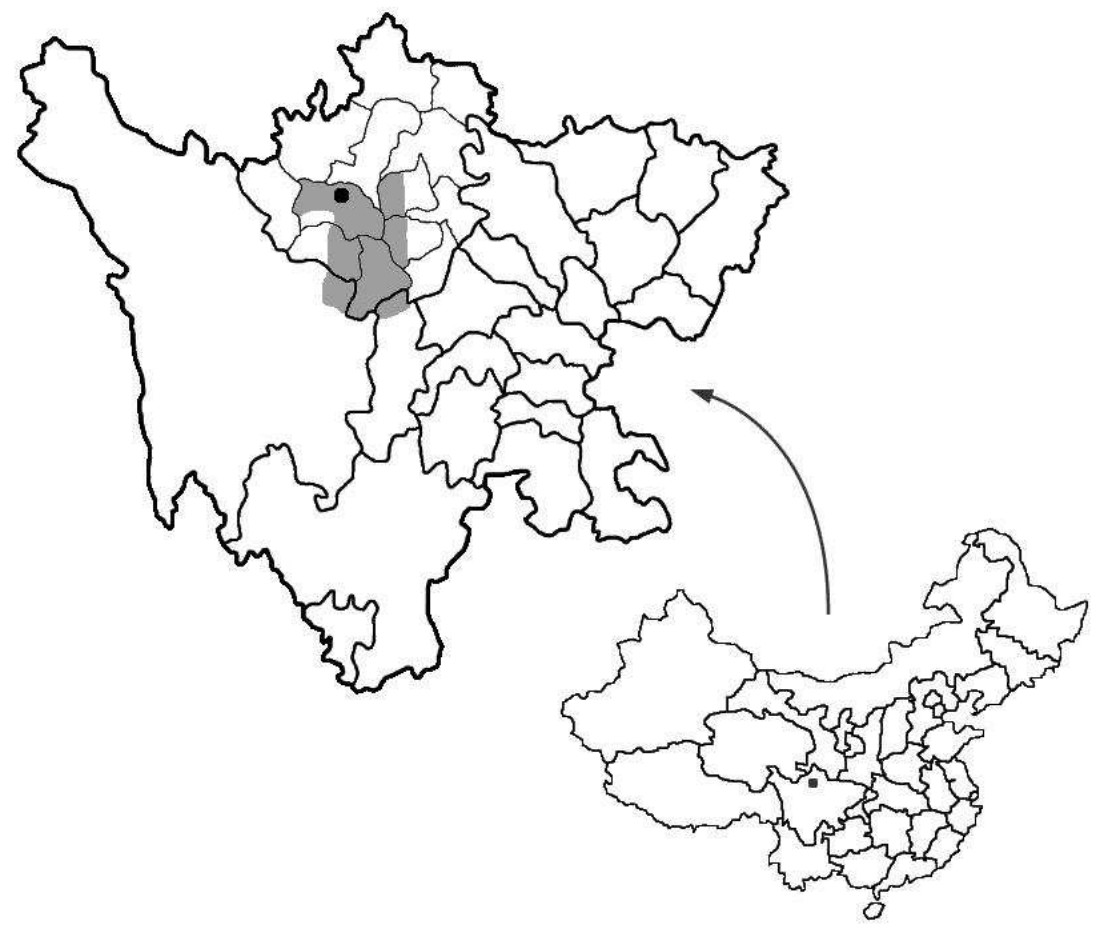

Figure 1: Rgyalrong languages

Rgyalrong languages are unwritten, except for some ancient texts in Situ in Tibetan script. Until the 1950s, these languages where under Amdo 
Tibetan influence, which is still conspicuous in the vocabulary, but now few speakers know Tibetan, while most of them are bilingual in Sichuan Chinese.

\subsection{Overview of Japhug morphosyntax}

Before studying the incorporation-like construction in detail, it is necessary to provide a general account of the main typological properties of the Japhug language. ${ }^{4}$

Japhug is a polysynthetic language, with obligatory person marking for two arguments and a direct / inverse system (see DeLancey 1981, Sun \& Shidanluo 2002 and Jacques 2010). The verb distinguishes between singular, dual and plural, but not inclusive/exclusive. Transitivity (a feature of crucial importance for our study of incorporation) is marked in five different ways:

1. The transitive aorist direct $3>3$ prefix $a-$

2 . The transitive aorist $1 / 2 \mathrm{sg}>3-t$ suffix (only occurs in open-syllable stem verbs)

3. The stem 3 formation, a stem alternation which occurs in direct $123 \mathrm{sg}>3$ forms of verbs. The regular pattern is that verbs whose stem is in $-\boldsymbol{o}$, $-u,-a$ and $-u$ change to $-r m,-e,-e$ and $-i$ respectively.

4. The generic A form (which cannot occur on intransitive verbs).

5. The A participle construction which differs from the $\mathrm{S}$ participle by the presence of a possessive prefix coreferent with the patient; compare the two phrases:

(5) $\quad$ ku-si

NMLZ:S/A-die

'The dead one'

(6) uu-ku-sat

3SG-NMLZ:S/A-kill

'The one who kills him.'

Tense-Aspect-Modality is marked by a combination of several series of directional prefixes with vowel alternation on the verb root. The structure of the verbal word is more templatic than layered (following Bickel \& Nichols 2007: 218's definition) and the basic template is the following:

\footnotetext{
${ }^{4}$ The reader can also refer to Jacques (2008), a preliminary grammar of Japhug, as well as to Sun (2003), a sketch of Tshobdun, the closest relative of Japhug.
} 
Table 1: The Japhug verbal template

\begin{tabular}{|c|c|c|c|c|c|c|c|c|c|c|c|c|c|c|c|c|c|}
\hline$a-$ & $\begin{array}{l}m u{ }^{-} \\
m \gamma-\end{array}$ & $\begin{array}{l}6 u I^{-} \\
\gamma u I^{-}\end{array}$ & $\begin{array}{l}t \gamma- \\
p u{ }^{-}\end{array}$ & tul- & $w \gamma^{-}$ & $z y^{\gamma}-$ & suI- & $r \gamma$ & $n \gamma$ & $\begin{array}{l}a- \\
s \gamma-\end{array}$ & nut- & $\begin{array}{l}y^{\gamma-} \\
r u-\end{array}$ & noun & $\Sigma$ & $-t$ & $-a$ & $\begin{array}{l}-n u I \\
-n d_{\not L I}\end{array}$ \\
\hline 1 & 2 & 3 & $\begin{array}{l}\text { etc. } \\
4\end{array}$ & 5 & 6 & 7 & 8 & 9 & 10 & 11 & 12 & $\begin{array}{l}\text { etc. } \\
13\end{array}$ & 14 & 15 & 16 & 17 & 18 \\
\hline
\end{tabular}

1. Irrealis $a-$, Interrogative $u^{\prime}-$, conative $j u-$

2. negation ma / mr / mu- / múuj

3. Translocative / Cislocative $6 u-$ and $\mathbf{y u -}$

4. Directional prefixes ( $t r-p u-I \gamma-t^{h} u-k \gamma-n u-j \gamma-t t^{42}$ pju- $\left.l u-c^{h} u-k u-j u-j u-\right)$ permansive nut, apprehe $\mathfrak{t}^{43}$ sive $6 u-$

5. Second person (tur,$k u-2>1$ and ta- $1>2$ )

6. Inverse $-w \gamma^{-} /$Generic S/O prefix ku-, Progressive asur-. Note that the inverse is actually infixed withiłf the progressive as in $л u-t u$ - $\boldsymbol{\gamma}<w \gamma>$ sul-zgros CONST-2 28 PROG $<$ INV $>$-attach "he is attaching you".

7. Reflexive $z \gamma^{\gamma}$

8. Causative su-, Abilitative su
9. Antipassive $s \boldsymbol{r}-\mathbf{r} \boldsymbol{r}$

240 10. Tropative $n \boldsymbol{r}$, applicative $n u-$

24 11. Passive or Intransitive thematic marker a-/ Deexperiencer $s \gamma$

12. Autobenefactive-spontaneous (appears in this position only when the passive/intransitive determiner is present, otherwise appears between positions 6 and 7) nur

13. Other derivation prefixes nu- yu- ru- nr $\gamma^{\gamma} r \boldsymbol{r}$

14. Noun root

15. Verb root

16. Past $1 \mathrm{sg} / 2 \mathrm{sg}$ transitive $-t$ (aorist and evidential)

17. $1 \mathrm{sg}-\boldsymbol{a}$

251 18. Personal agreement suffixes $(-t \boldsymbol{t} \boldsymbol{i},-j i,-n u,-n d \not \boldsymbol{i})$ 
Japhug and other Rgyalrong languages are typologically unusual in being verb-final languages with mainly prefixing morphology. It is quite common to find a verb form with more than four or five prefixes in a row:

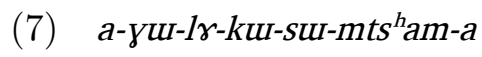
IRR-CISL-PFV:upstream-2>1-CAUS-hear-1SG

You will come to tell me. (Japhug; The three sisters, 132)

Derivational morphology is also extensive: argument-promoting (causative, applicative, tropative), demoting (passive, antipassive, anticausative etc) and modal (abilitative, facilitative) derivations are all attested and fairly productive (see for instance Jacques 2012b or Sun 2006 on the related Tshobdun language).

Japhug is a strongly head-marking language, and its case marking system is rather poor: it only has an ergative clitic ku, an optional genitive yu and an optional locative zu.

From the point of view of alignment typology, Japhug has ergative marking on nouns, tripartite alignment in relativization and ergative alignment in generic marking (cf Jacques 2012b).

Japhug has a strong distinction between nouns and verbs, a feature, which as we have argued in section 2 , is a prerequisite for the existence of incorporation. Nouns, unlike verbs, exhibit little morphology except possessive prefixes, whose paradigm is given in the following table, compared to the free pronouns (these prefixes also occur in some participial verb forms):

Table 2: Pronouns and possessive prefixes in Japhug

\begin{tabular}{|c|c|c|}
\hline Free pronoun & Prefix & \\
\hline ақо & $a-$ & $1 \mathrm{SG}$ \\
\hline nґъo & $n \gamma-$ & $2 \mathrm{SG}$ \\
\hline шъо & $u-$ & $3 \mathrm{SG}$ \\
\hline tढ़izo & $t \varphi i_{-}$ & $1 \mathrm{DU}$ \\
\hline ndzizo & $n d_{\not{q}} i_{-}$ & $2 \mathrm{DU}$ \\
\hline zrni & $n d \not z i-$ & 3DU \\
\hline iъ̧o & $i-$ & $1 \mathrm{PL}$ \\
\hline пшъо & $n u-$ & $2 \mathrm{PL}$ \\
\hline zara & $n u-$ & $3 \mathrm{PL}$ \\
\hline
\end{tabular}

Some intrinsically possessed nouns, especially body parts, kinship terms and relational nouns, must appear with either a possessive prefix or the indefinite possessive $t u r$ or $t r$.

Finally, we are going to address the definition of wordhood in Japhug, which is crucial to any discussion on derivational morphology. In some languages of the Sino-Tibetan family such as Galo (see Post 2009) it has 
been shown that the phonological and morphological boundaries are not always congruent. In Limbu, Hildebrandt (2007) and Schiering et al. (2010) have suggested that a phonological boundary exists between prefixes and the rest of the verbal word, as indicated by two phonological rules (glottal-stop insertion and non-application of $\mathrm{l} / \mathrm{r}$ alternation).

In Japhug, there is also some evidence for the existence of a phonological boundary within the morphological verbal word.

Unlike other Rgyalrong languages (see Sun 2005), Japhug has lost tonal and stress contrasts, and the stress always falls on the last syllable of the word, except in two cases.

First, some verbal prefixes, in particular the inverse $-w \gamma^{-}$, attract stress on the preceding syllable, as in the following example:

(8) púr-wy-mto-a-ndzi

AOR-INV-See-1SG-DU

They ${ }^{d}$ saw me. (elicitation, Chen Zhen).

Second, personal agreement suffixes are always unstressed and the vowels of these suffixes are often devoiced: ${ }^{5}$

(9) puu-mtó-t-a-ndz̧i [pumtótandz̧i $]$

AOR-See-PST-1SG-DU

I saw them ${ }^{d}$. (elicitation, Chen Zhen).

In our transcription of Japhug, stress is only indicated in the case of stress-attracting prefixes, as its placement is always predictable otherwise.

Stress in Japhug is a valuable indicator of phonological domains, and the facts presented above suggest that a phonological boundary exists between the verb stem and the agreement suffixes, in other words between position 16 and position 17 of the verbal template. ${ }^{6}$

In Limbu and most other Kiranti languages, Schiering et al. (2010) argued that / /-insertion between verbal prefixes and vowel-initial root (as in $/ k \varepsilon$-im/ 2-sleep "you sleep" realized as [ke?im]) was a marker of phonological boundary. In Japhug, no such insertion is observed: vowel fusion between the prefix and the verb stem always occurs. For instance, the second person non-past form of $/ a \varphi q^{h} e /$ "to cough" is /tul-r $\zeta q^{h} e / 2$-cough $\left[t r G q^{h} e\right]$, not *tuPacq $q^{h}$. All other elements occurring to the right of the second person prefix and to the left of the verb root (positions 7 to 14, including all derivation prefixes as well as nominal roots) belong unequivocally to the same phonological word.

${ }^{5}$ The only exception is the first person singular suffix $-a$ when it merges with the verb stem, as in $t \gamma$-a $q^{h}$ e-a AOR-cough-1SG "I coughed" realized as [tac $q^{h} j a ́$.

${ }^{6}$ See Gong (to appear) for a similar claim concerning Zbu Rgyalrong. 


\subsection{Incorporation-like verbal compounds}

Japhug presents verbal compounds that superficially resemble incorporational constructions. These verbal compounds include a nominal and a verbal root, both of which can appear independently, are not restricted to non-finite forms and belong to the same phonological word, as defined in the previous subsection. Therefore, they would seem to fulfil the definition of incorporation presented in section 2. However, we will see in the following sections that these compounds also show some affinities with denominal derivations. Their exact status will be discussed in sections 5 and 6 , and we will non-committally refer to this construction as incorporation-like construction (ILC) in this article.

Unlike other derivational processes, ILC verbs are not very numerous in Japhug: only 36 have been discovered up to now out of a total of 1800 verbs in our unpublished lexical database. Although ILC is fairly rare in traditional stories, these examples show that this process is still productive, as it applies not only to native vocabulary, but also to Tibetan ( f $о в$ "earn" $<$ Tibetan bsogs), u-nrm "flesh" < nyam) and Chinese ( $t s^{h_{a}}$ "tea" 茶 chá, pсawtsu "money" 票子 piàozi) loanwords. Chinese loanwords are almost all extremely recent, dating from after 1950.

In the following table, noun roots in ILC verbs are written in bold, and separated from other morphemes by a hyphen. For each ILC verb, we list the base noun and verb from which it is built. Note that some of the nouns are intrinsically possessed nouns, and must appear with a possessive prefix (here systematically given as the third person $u-$ ) or the indefinite possessive $t u r$.

Verbs for which we have indicated idiom as the meaning only appear in noun-verb collocations with the same noun as in the ILC verb. For instance tur-zi $1 о в$ is an idiom meaning "have nausea":

\section{(10) шио ши-ъi ли-Іов}

he 3SG.POSS-nausea CONST-have.nausea

He has nausea. (elicitation, Dpalcan)

Neither the noun tur-zi nor the verb though they behave morphologically like independent words, but the ILC equivalent пи-zш-lов "have nausea" constitutes a single word.

The morphological and morphosyntactic properties of these ILC verbs will be analysed in the following sub-sections. 
Table 3: Examples of ILC in Japhug

\begin{tabular}{|c|c|c|c|c|c|}
\hline base noun & meaning & base verb & meaning & ILC verb & meaning \\
\hline$t u r-k u$ & head & amtcos & pointed (vs) & $a-k \boldsymbol{r}-m t \epsilon O B$ & having a pointed head \\
\hline$c^{h} a$ & alcohol & $t s^{h} i$ & drink (vt) & $\gamma u-c^{h} \gamma-t s^{h} i$ & to drink alcohol \\
\hline$c u I$ & stone & $p^{h} u t$ & take out, cut down (vt) & yu- $\boldsymbol{c u}-p^{h} u t$ & to take out stones (out of the field) \\
\hline$t u-\gamma l i$ & dung & t6rt & take out (vt) & $\gamma u-\gamma l u-t c \gamma t$ & $\begin{array}{l}\text { to take out dung (out of the stable, } \\
\text { to make fertilizer) }\end{array}$ \\
\hline$\gamma n d \not r \beta$ & fire (big) & ta & put (vt) & $z u-y n d z r \beta-t a$ & to clear (fields) with fire \\
\hline$k^{h}$ una & $\operatorname{dog}$ & $t s^{h} O B$ & $\operatorname{attach}(v t)$ & $\gamma u-\boldsymbol{k}^{\boldsymbol{h}} \boldsymbol{u}-t s^{h} O B$ & to turn the dog loose on \\
\hline pcawtsu & money & fsОв & earn & уші-pсawtsu-fsö & to earn money \\
\hline tuu-rfu & riches & fsOB & earn & yUI-rjü-fSOB & to earn riches \\
\hline si & tree, wood & $p^{h} u t$ & take out, cut down (vt) & $\gamma u$-sur-pht $p^{h} u t$ & to cut wood (to make firewood) \\
\hline$t s^{h} a$ & tea & $t s^{h} i$ & drink (vt) & $\gamma u-t s^{h} \gamma-t s^{h} i$ & to have tea \\
\hline tstu & way & $m t s^{h} i$ & lead (vt) & $\gamma u-t_{\boldsymbol{S}} \gamma-m t^{h_{i}}$ & to lead the way \\
\hline$t \gamma-j l \gamma \beta$ & steam & sqa & $\operatorname{cook}(\mathrm{vt})$ & $n \gamma-j 1 \gamma \beta-s q a$ & to cook with steam (vt) \\
\hline tur-ku & head & $t \epsilon^{h} u I$ & gore (vt) & $n \boldsymbol{\gamma}-\boldsymbol{k} \boldsymbol{\gamma}-t \epsilon^{h} u$ & to hit with the head (vt) \\
\hline tus-zgru & elbow & $t \epsilon^{h} u$ & gore (vt) & nut-zgruu-t $\phi^{h} u$ & to hit with the elbow (vt) \\
\hline$u-m p^{h} r u$ & one after the other & za & start (vt) & $n \gamma-m p^{h} r u-z a$ & to do after after the other \\
\hline$t \gamma-p^{h} u I$ & clod (of earth) & xtsui & pound (vt) & $n \gamma-p^{h} u-x t s u I$ & to break clods of earth \\
\hline$u-q a$ & root & za & start (vt) & $n \gamma-q a-z a$ & to start from the beginning (vt) \\
\hline$u-q^{h} u$ & back, behind & $r u$ & look & $n \gamma-q^{h} a-r u$ & to look back \\
\hline$u-q^{h} u$ & back, behind & nga & wear (vt) & $n \gamma-\boldsymbol{q}^{h} \gamma-\eta g a$ & to wear on the back \\
\hline$t u-\not i$ & nausea & $1 о в$ & (idiom) & $n \gamma-z u-l o в$ & to have nausea \\
\hline jla & hybrid yak & $1 \gamma \gamma$ & herd (vl) & $n u-j 1 \gamma-1 \gamma \gamma$ & to herd hybrid yaks \\
\hline jla & hybrid yak & $m t s^{h} i$ & lead (vt) & $n u-j l \gamma-m t s^{h} i$ & to lead hybrid yaks \\
\hline mbro & horse & rfur & run & nut-mbry-rfur & to gallop \\
\hline tuu-ña & debt & tso & pay & nu-nךr-tso & to pay back one's debt \\
\hline
\end{tabular}




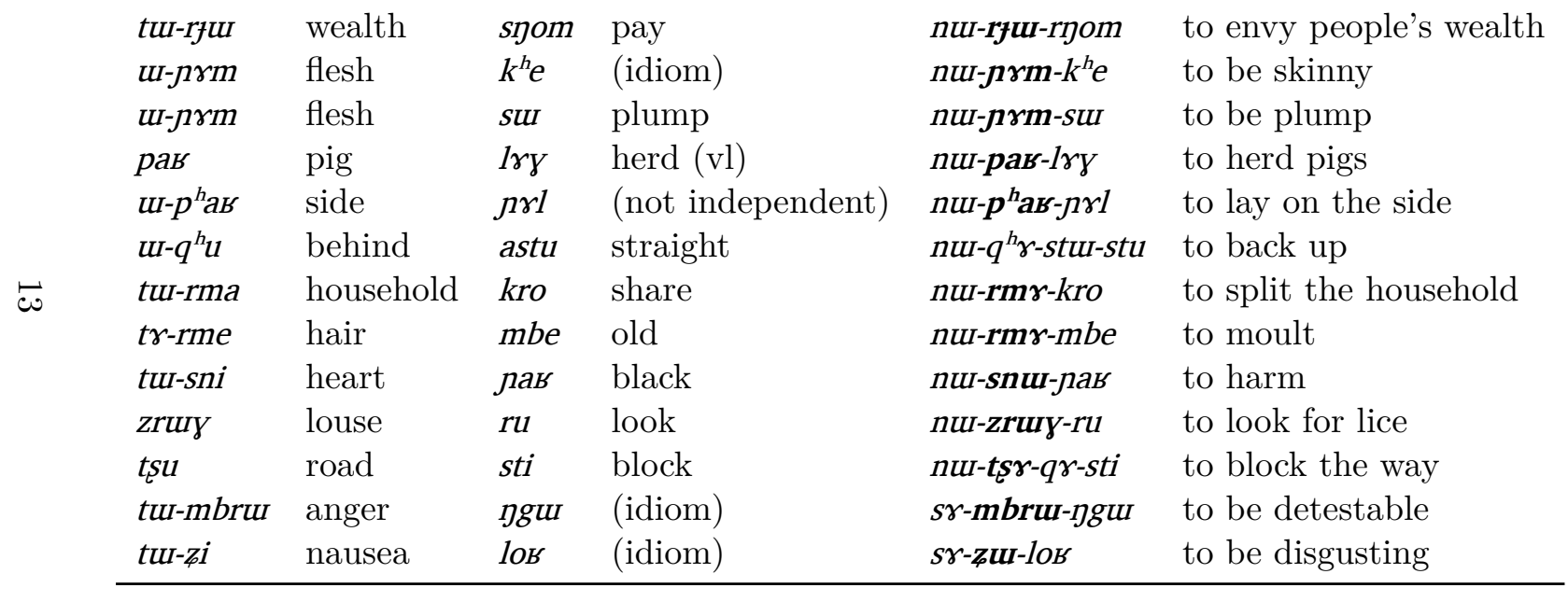


Aside from the 35 examples above, a special case must be made of the verb krtupa "to speak". This verb etymologically includes the verbal root -pa, which originally meant "to do", but has become restricted in modern Japhug to the meaning "to close (the door)" or as a light verb with ideophones. The first part $k r t u r$ is an ablauted form of $k \boldsymbol{r}$-ti the patient participle of the verb $t i$ "to say" and literally means "the things that are said" (in some contexts it also means "niggling").

krtupa is a defective verb, and only occurs in non-past first and third person forms. It is morphologically transitive, and undergoes $-\boldsymbol{a}>-\boldsymbol{e}$ ablaut in singular forms. The following table compares the non-past (direct, i.e. with a third person patient) forms of the transitive verb ndza "to eat" with those of krtupa:

Table 4: Paradigm of the verb krtupa "to speak"

\begin{tabular}{lll}
\hline Person & "to eat" & "to speak" \\
\hline 1SG & ndze-a & krtupe-a \\
2SG & tur-ndze & XX \\
3SG & ndze & krtupe \\
1DU & ndza-tci & krtupa-tci \\
2DU & tu-ndza-ndzi & XX \\
3DU & ndza-ndzi & krtupa-ndzi \\
1PL & ndza-j & krtupa-j \\
2PL & tu-ndza-nut & XX \\
3PL & ndza-nut & krtupa-nu \\
\hline
\end{tabular}

The non-past being the only tense which is not prefixed in Japhug, we observe that the only attested forms of this verb are precisely those which are not prefixed; in other words, the verb krtupa "to speak" is one of the few verbs in the language (alongside the highly irregular zrzu "to be there" and mane "not to be there") which cannot appear with any prefix.

\subsection{Morphological properties}

All ILC verbs in Japhug except krtupa "to speak" exhibit a very strict morphological structure, which we can represent as follows:

DERIVATIONAL PREFIX NOMINAL STEM VERBAL STEM $n u-, n \gamma^{-}, \gamma^{\prime}{ }^{-}, \mathrm{sr}$

A few examples such as nutsrqrsti "to block the way" present more than one nominal element, but we will first restrict the discussion to this basic structure. This structure, interestingly, is the mirror-image of the Algonquian incorporational construction INITIAL + MEDIAL + FINAL mentioned in section 2 . 
The nature of the derivational prefixes is analysed in more detail in section 5; it will be shown that these prefixes are homophonous with denominal prefixes, and that the ILC presents affinities with denominal constructions.

For the time being we remain non-committal as to whether ILC constitutes true incorporation or a different construction altogether, and will therefore avoid using the term "incorporation" until section 5, when all the facts have been laid out and analysed. The verbs showing this construction will be called "ILC verbs" and the nominal stem that appears in this construction "ILC nominal stem" (rather than "incorporated noun").

The nominal stem in the ILC differs from the free form in two ways. First, in the case of possessed noun prefixes with either the indefinite possessive prefix $t u r-/ t r$ or the third person prefix $u r$, this prefix disappears in the ILC. Second, in open-syllable nouns, the vowel undergoes a series of regular changes, which we call the status constructus:

Table 5: Status constructus

\begin{tabular}{ll}
\multicolumn{2}{c}{ Table 5: Status constructus } \\
\hline basic noun & incorporated noun \\
$-a$ & $-\gamma /-a$ \\
$-o$ & $-\gamma /-a$ \\
$-e$ & $-\gamma /-a$ \\
$-u$ & $-\gamma /-a$ \\
$-i$ & $-u$ \\
\hline
\end{tabular}

The status constructus of some nouns is irregular, in particular the noun "dog" $k^{h}$ una which becomes $k^{h} u$ - instead of expected ${ }^{*} k^{h} u n r$. Not only possessive prefixes are lost during derivation, but also derivational prefixes as

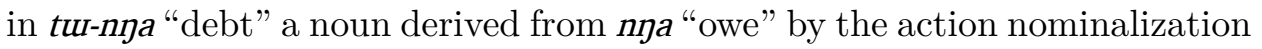
prefix tur. The only case of a prefix preserved in the status constructus in

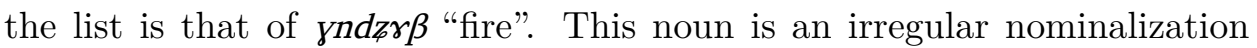
of $n d_{\mathrm{r} r} \beta$ "to burn (vi)", an anticausative derivation of the transitive $\operatorname{tcr} \beta$ "burn (vt)". The regular form ku-ndzr $\beta$ is also attested; $\gamma^{-}$originates from kur - by syncope (a cluster such as /knd / would be impossible in Japhug). The reason for the preservation of this $\gamma^{-}$element is that it is not perceived synchronically to be a prefix.

The status constructus is not limited to ILC verbs, but also occurs in nominal compounds:

Table 6: Examples of noun compounds with status constructus

\begin{tabular}{|c|c|c|c|c|c|}
\hline $\begin{array}{l}\text { Element } 1 \\
\text { tut-ku } \\
t_{S} u\end{array}$ & $\begin{array}{l}\text { meaning } \\
\text { head } \\
\text { road }\end{array}$ & $\begin{array}{l}\text { Element } 2 \\
\text { tr-rme } \\
\text { tr-m } m t^{h} \text { um }\end{array}$ & $\begin{array}{l}\text { meaning } \\
\text { hair } \\
\text { meat }\end{array}$ & 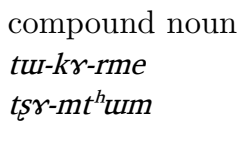 & $\begin{array}{l}\text { meaning } \\
\text { hair (on the head) } \\
\text { provision of } \\
\text { meat for the road }\end{array}$ \\
\hline
\end{tabular}


The first element is always a noun in status constructus, and the second element undergoes little change, except for the loss of possessive prefixes.

The presence of a distinct bound form for nominal stems in ILC, and the fact that this bound form also occurs in nominal compounds, are characteristics also attested in many languages with incorporation, in particular the Algonquian examples discussed in section 2.

\subsection{Syntactic properties}

ILC verbs are not common in traditional stories, so that a detailed study of the function of this construction is difficult.

The ILC nominal stem cannot be modified by either stranded demonstratives or adjectives as in languages such as Hopi (see for instance Haugen 2008: 121), and it is never referential. Although ILC retains some degree of productivity, attempts at creating new ILC verbs on the model of the ones discovered in the stories met with disagreement by the speakers. For

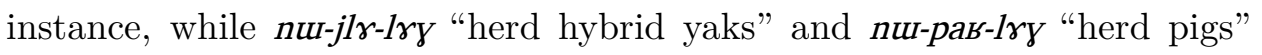
are possible, it is impossible (or at least not fully acceptable) to produce a verb such as *nu-qazr-Iry "herd sheep", probably because such an activity is not in Rgyalrong culture "recognized sufficiently often to be considered name-worthy in its own right", as Mithun (1984: 848) puts it.

The ILC nominal stem can have three functions:

(11) O of a transitive verb: yuu-sur-p $p^{h} u t$ "cut wood".

$\mathrm{S}$ of an intransitive verb: $\boldsymbol{a}-\boldsymbol{k} \boldsymbol{\gamma}$-mtсos "have a pointed head".

Adjunct: $n \boldsymbol{r}-\boldsymbol{q}^{\boldsymbol{h}} \mathbf{a}-\mathrm{ru}$ "look back".

Note that no examples of A have been discovered: the Japhug ILC follows the well-known implicational hierarchy of incorporating constructions, according to which "if a language incorporates nouns in just one function, they will be direct objects; if a language incorporates only two types of arguments, they will be direct objects and subjects of intransitive verbs" (Aikhenvald 2007: 19).

When the ILC nominal stem corresponds to the $\mathrm{O}$ of the original verb, the ILC verb becomes intransitive: this is a situation similar to saturating incorporation (type I incorporation according to Mithun (1984)'s hierarchy). Compare the two following competing constructions:

\section{(12) nuu-nul-ngr-tso-a}

AOR-DERIVATION-debt-pay-1SG

(13) a-nna nu-tso-t-a

1SG.POSS-debt AOR-pay-PST-1SG

I paid my debt. (elicitation, Chen Zhen) 
In example 13 without ILC, the verb tso "to pay", is transitive, as shown the presence of the past suffix $-t$, which only occurs in $1 \mathrm{SG}>3$ and $2 \mathrm{SG}>3$ forms of transitive verbs. In the corresponding ILC verb in example 12, the verb cannot appear with this suffix $-t$, showing that it was intransitivized by the process of incorporation.

When the ILC nominal stem corresponds to the $\mathrm{S}$ of the original verb, the verb remains intransitive. In at least one example, the samenominal root appears both within the ILC verb and as the free noun S-argument (tur-ku "head" becomes $-\boldsymbol{k r}$ - in status constructus):

\section{(14) (i) u-ku лит-rmt6ов 3sG-head CONST-pointed}

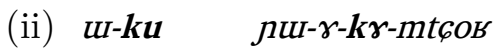
3SG-head CONST-DERIVATION-head-pointed Its head is pointed (of a knife). (elicitation, Dpalcan)

When the ILC nominal stem corresponds to an adjunct, the verb remains transitive in some cases, as in $n r k r t \epsilon^{h} u$ "hit with the head":

(15) $\quad k \gamma^{\prime}-w \gamma-n \gamma-k \gamma-t c^{h} u-a$

AOR-INV-DERIVATION-head-gore-1SG

He hit me with his head. (elicitation, Dpalcan)

However we have found no case of ILC similar to Mithun's type II incorporation, when a verb incorporating an $\mathrm{O}$ argument remains transitive, and promotes an adjunct to $\mathrm{O}$ role.

Although the meaning of some of the ILC verbs is not compositional, in other words one cannot guess the exact meaning of the verb from that of the ILC nominal stem and the verb, some ILC verbs are quite transparent in this regard. This is for instance the case of yu-pсawtsu-fsos "earn money", a recent ILC verb since it contains a Chinese loanword.

We find the following two examples a few sentences apart in the same story:

(16) tasa ju-ku-ce tce, nutcu pøawtsu $k \gamma-f s o b$

Lhasa IPF-GENR:S/O-go COORD there money INF-earn nut-mbat

CONST-easy

'If one goes to Lhasa, it is easy to earn money there.' (Lobzang, 22)

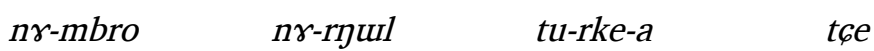

2SG.POSS-horse 2SG.POSS-silver IPF-put.in[3]-1SG COORD

ku- -шu-pфаwtsu-fsos jr-ce tсе

NMLZ:S/A-DERIVATION-money-earn IMP-go COORD

'I will prepare a horse and some silver for you, go and earn some money.' (Lobzang, 17) 
In the first example, pcawtsu "money" is the free object of the transitive verb $f_{\text {sos }}$ "earn". In the second sentence, we find the corresponding ILC verb. In both cases, the Noun-Verb construction and the ILC verb could have been substituted one for the other without any noticeable change of meaning.

Interestingly, an important proportion (more than half) of textual examples of compositional ILC verbs such as these are found as non-finite verbal forms, especially as complements of movement verbs:

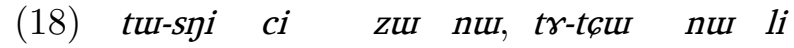

one-day INDEF LOC TOP NEU-boy TOP again

ku- yut-sur-p $p^{h}$ ut $\quad$ lr-ari

NMLZ:S/A-DERIVATION-wood-chop AOR:UPSTREAM-go[II]

дит-пu,

CONST-be

'One day, the boy went again to chop wood.' (The demon, 7)

These ILC verbs differ from constructions such as English go berrypicking, as they can be fully conjugated, but the prevalence of these verbs in non-finite forms in spontaneous speech deserves a more detailed study. More conversations and traditional stories need to be collected in order to be able to undertake meaningful statistical studies.

\section{Denominal derivation in Japhug}

Japhug has a very rich system of denominal derivations, which cannot be treated exhaustively in this article. All denominal verbs are derived from nouns by means of a derivational prefix. The attested prefixes are the following:

Table 7: List of denominal prefixes in Japhug

\begin{tabular}{|c|c|}
\hline Form & Transitivity \\
\hline$n u t, n r$ & intransitive and transitive \\
\hline$r u-, r r$ & intransitive and transitive \\
\hline$\gamma u-, \gamma^{\gamma}$ & intransitive and transitive \\
\hline sut- & transitive verb with instrument, intransitive verb of position \\
\hline$m r$ & transitive verb with body part, intransitive verb of position \\
\hline$s \gamma$ & intransitive verb (property) \\
\hline аушт - & intransitive verb (property) \\
\hline
\end{tabular}

Many denominal verbs are derived from intrinsically possessed nouns, which always bear either a possessive prefix or an indefinite possessor prefix $t u$ - or $t r$. The vocalism $/ u /$ or $/ \gamma /$ of the denominal prefixes depends on 
whether the base noun has tur or $t \boldsymbol{r}$-, though there are a few exceptions. For instance, from $\boldsymbol{t} \boldsymbol{\gamma}$-zri "dew" one can derive $\boldsymbol{n} \boldsymbol{\gamma}$-zri "be covered with dew" (vi), while from tu-zu $\beta$ "sleep (n)" one derives пш-цu $\beta$ "sleep (vi)". However, numerous exceptions to this general principle exist; in particular, the vowel $/ u /$ tends to be realized closer to $[\gamma]$ next to a uvular consonant.

There are several pairs where $n u-/ n \boldsymbol{r}$ - derives a transitive verb while $r u-/ r \gamma$ - derives an intransitive one, such as tur-krrz "discussion" > nukrrz "discuss (vt)" vs. rrkrrz "discuss (vi)".

However, the transitivity of the derived verb is not always predictable from the form of the prefix. The following table illustrates the transitivity of the denominal verbs depending on their derivational prefix (the number refer to occurrences in my unpublished Japhug dictionary):

Table 8: Proportion of transitive and intransitive verbs

\begin{tabular}{|c|c|c|}
\hline Form & \multicolumn{2}{|c|}{ Transitivity } \\
\hline & vi & $\mathrm{vt}$ \\
\hline$n u t, n \gamma$ & 44 & 46 \\
\hline$r u r, r r$ & 28 & 4 \\
\hline$\gamma u-, \gamma^{\gamma}$ & 6 & 8 \\
\hline sut & 2 & 5 \\
\hline$m r$ & 2 & 3 \\
\hline$s \gamma$ & 2 & 0 \\
\hline аушт & 12 & 0 \\
\hline
\end{tabular}

Discussing in detail the semantic properties of each prefix would require considerable space and will not be attempted in this article. We will only focus on the functions of the five forms that denominal verbs and incorporating verbs have in common: nur, nr-, уUг, sur and $s r^{-}$.

The prefix $n u-$ and its variant $n \boldsymbol{r}$ - appear in a considerable variety of verbs, as illustrated in table 9 . 
Table 9: Examples of the denominal prefix nur

\begin{tabular}{|c|c|c|c|c|}
\hline Base noun & Meaning & Derived verb & Meaning & \\
\hline$u-p^{h} u$ & price & $n u-p^{h} u$ & to be of a correct price & vi, stative \\
\hline sya & rust & nu-sya & to be rusty & vi, stative \\
\hline qafy & fish & nu-qafy & to fish & vi \\
\hline tul-pgra & salary & nu-pgra & to receive a salary & vi \\
\hline$m t^{h} u I$ & spell & $n u-m t^{h} u$ & to cast a spell & $\mathrm{vt}$ \\
\hline kuujin & oath & nu-kujinu & to swear & $\mathrm{vt}$ \\
\hline mburlrn & plane & nu-mburlrn & to plane & vt \\
\hline smrn & medicine & nu-smrn & to treat & $\mathrm{vt}$ \\
\hline mkryur & necklace & nu-mkrушur & to wear as a necklace & $\mathrm{vt}$ \\
\hline tü-rdos & a piece & пи-гdов & to pick up piece by piece & vt \\
\hline вјов & servant & пит-вјов & to give orders to & $\mathrm{vt}$ \\
\hline sgra & enemy & nut-sgra & to treat as an enemy & $\mathrm{vt}$ \\
\hline tuu-sk ${ }^{h} r u$ & body & $n u-s k^{h} r u u$ & to be pregnant & vt \\
\hline
\end{tabular}

The prefix nu- can derive four major types of verbs, though some (such as "to be pregnant") cannot be easily classified into any category.

First, nur derives intransitive stative verbs denoting a property related to the base noun, as in "to be rusty" and "to be of a correct price".

Second, nu- is used to create intransitive verbs describing an activity whose purpose is to obtain the entity designated by the base noun, as in "to fish" or "to receive a salary"; the meaning is never "to make X" or "to become X".

Third, the prefix nu- derives transitive action verbs from instrument nouns (as in "to plane" or "to treat").

Fourth, nu- forms transitive verbs meaning "to consider as, to treat as" relative to the base noun.

The prefix $\gamma^{\prime}$ - is much less common than nu-. The following examples illustrate its main functions:

Table 10: Examples of the denominal prefix $у ш-$

\begin{tabular}{|c|c|c|c|c|}
\hline Base noun & Meaning & Derived verb & Meaning & \\
\hline tr-tsruu & sprout & $y^{\gamma}$-tsruu & to sprout & vi \\
\hline contca & timber & $\gamma u-c o \eta t c a$ & to chop timber & vi \\
\hline$t u-t c^{h} a$ & message & $y u-t c^{h} a$ & to answer & $\mathrm{vt}$ \\
\hline ckat & load & yu-ckat & to load (an animal) & $\mathrm{vt}$ \\
\hline tr-fkumm & bag & yu-fkum & to put in a bag & $\mathrm{vt}$ \\
\hline
\end{tabular}

The allomorph $\gamma^{\gamma}$ - only occurs with intransitive verbs expressing the generation of the entity designated by the base noun (as in "to sprout"). Some uses of yu- seem to be identical to that of nur-. For instance, the case 
of "to chop timber" is similar to that observed with the verb num-qafy "to fish" above. Verbs such as zu-ckat "to load" and yu-fkum "to put in a bag" on the other hand exemplify a type of derivation slightly different from that of nur-, meaning especially "to put in a container", the container being the base noun.

The prefix sur- appears in two cases. First, with body parts or instruments, where it derives a labile or a transitive verb expressing the action of that instrument (tu-jasndzu "finger" > su-jasndzu "show with the finger"). Second, with nouns expressing a position such as ndzupe "way of sitting (without crossing legs, the way women sit in the Rgyalrong traditional society) > su-ndzupe "sit (without crossing legs, vi)".

\subsection{Deexperiencer / tropative pairs}

Aside from the three groups of prefixes nu- / nr-, gur-and sur-discussed above, we must mention the case of the deexperiencer / tropative pairs in $s \gamma$ - $n \boldsymbol{r}$ - (see table 11 for examples of these prefixes), in relation to the pair of ILC verbs $\boldsymbol{s \gamma - z u - l o b ~ " t o ~ b e ~ d i s g u s t i n g " ~ a n d ~} n \boldsymbol{n}$-zu-los "to have nausea" derived from the collocation $t u-z i$ los "to have nausea".

The deexperiencer prefix $\boldsymbol{s} \boldsymbol{\gamma}$ - derives an intransitive stative verb out of either transitive (perception verbs) or intransitive verbs, and the $\mathrm{S}$ of the deexperiencer verbs corresponds to the stimulus of the base verb, while the original S or A is demoted (see Jacques 2012b). The tropative derivation derives a transitive verb from a stative verb, by adding an experiencer (which becomes the $\mathrm{A}$ of the derived verb) while the $\mathrm{S}$ of the original verb becomes the $\mathrm{O}$. This derivation differs from the causative in that the resulting verb always has the specific meaning "to find / consider XXX".

Table 11: Examples of the deexperiencer and tropative verbs

\begin{tabular}{|c|c|c|c|}
\hline Basic verb & meaning & Derived verb & meaning \\
\hline ngio & to slip & sr-ngio & to be slippery (of the ground) \\
\hline cke & to be burned & $s \gamma-c k e$ & to be burning \\
\hline rga & to like (itr.) & $s \gamma-r g a$ & to be nice \\
\hline wxti & to be big & $n \gamma-w x t i$ & to consider to be too big \\
\hline & to be long & $n \gamma-z r i$ & to consider to be too long \\
\hline mnrm & to have an odour & $n \gamma-m n r m$ & to smell (tr.) \\
\hline
\end{tabular}

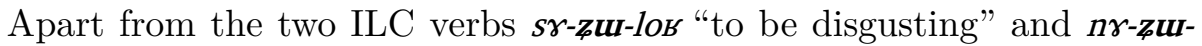
$1 о в$ "to have nausea", we find three pairs of verbs which present the same apparent meaning derivation: 
Table 12: Deexperiencer / Tropative pairs

\begin{tabular}{|c|c|c|c|c|c|}
\hline $\begin{array}{l}\text { Deexperiencer } \\
\text { verb }\end{array}$ & Meaning & $\begin{array}{l}\text { Tropative } \\
\text { verb }\end{array}$ & Meaning & Noun & Meaning \\
\hline sr-re & to be ridiculous & $n \gamma-r e$ & to laugh (labile) & $t \gamma-r e$ & laughter \\
\hline$s \gamma-m t s^{h} \gamma r$ & to be strange & $n \gamma-m t s^{h} \gamma r$ & $\begin{array}{l}\text { to consider }(\mathrm{vt}) \\
\text { to be strange }\end{array}$ & $t \gamma-m t s^{h} \gamma r$ & $\begin{array}{l}\text { strange } \\
\text { event }\end{array}$ \\
\hline$s \gamma-\eta \gamma \gamma \beta$ & $\begin{array}{l}\text { to be such that } \\
\text { people are reluctant } \\
\text { to do it }\end{array}$ & $n \gamma-\eta \gamma \beta$ & to be reluctant to (vt) & & \\
\hline
\end{tabular}

The verb $n \boldsymbol{r}$-re is labile, meaning "to laugh at (someone)" when used transitively, and "to laugh" when used intransitively.

The first two verb pairs $s \gamma-r e / n \gamma-r e$ and $s \gamma-m t s^{h} \gamma r / n \gamma-m t s^{h} \gamma r$ are similar, related to base nouns prefixed in $t r$. Note that the prefix in these nouns is the indefinite possessive, which disappears when a possessive prefix is added:

(19) uा-re ci दmur jr-clur,

3SG.POSS-laughter a.little IDEO:1:laughter EVD-drop

She (could not resist and) laughed a little. (The Frog, 100)

For the pair srgr $\beta$ / nrgr $\beta$ on the other hand, no corresponding noun seems to exist, though it could have existed or be attested in other varieties of Japhug.

It would appear that the pairs of verbs in Table 12 are derived from the nouns, and thus that the deexperiencer and tropative prefixes can be used as denominal markers alongside their regular use. However, from a comparative point of view, the root of $t \boldsymbol{\gamma}$-re "laughter" is clearly verbal in origin (see for instance Tangut rjijr ${ }^{2}$, proto-Lolo-Burmese * ray $^{1}$, both "to laugh", Matisoff 2003: 43). Besides, $t \gamma-m t s^{h} \gamma r$ is a loanword from the Tibetan $m t s^{h} a r . b a$ "to be fabulous, to be strange". This suggests that $t \gamma-r e$ "laughter" and $t \gamma-m t s^{h} \gamma r$ "strange event" are deverbal nouns, and that unattested verbal roots *re and ${ }^{*} m t s^{h} \gamma r$ must have existed at an earlier stage.

The following scenario can be postulated to explain these forms. If we assume the existence of an intransitive verb *are "to laugh" (intransitive) with the thematic element $a-{ }^{7}$ its regular deexperiencer would be ${ }^{*} s$-are $>$ sr-re.

One can also regularly derive from *are "to laugh" the deverbal noun $t \gamma-r e$ "laughter (n)"; such examples are quite common, for instance the derivation $a \epsilon q^{h} e$ "to cough" > tr- $6 q^{h} e$ "cough (n)".

\footnotetext{
${ }^{7}$ This thematic element appears on many intransitive verbs, including stative (amt6os "pointed", artum "round") and dynamic ones (acq $q^{h}$ "to cough", atur "to meet"). It historically originates from an intransitivizer (still reflected in the passive derivation $a-$ ) but synchronically the $a$ - in these verbs must be analyzed as a part of the stem, as no corresponding prefixless verb exists.
} 
Finally, nu-are > nrre "to laugh at" would be the regular applicative (not tropative) of the verb ${ }^{*}$ are $^{8}$ This hypothetical form * are in turn would be derived from a root *re "to laugh at (tr)", in the same way as $a k^{h} u$ "to call" must originate from a transitive root ${ }^{*} k^{h} u$ "to call (transitive)". The Tangut and Lolo-Burmese form reflect the non-derived root ${ }^{*} r e$, while the Japhug forms have undergone several layers of derivation.

The disappearance of * are (and other comparable forms) makes the formation quite opaque.

For $s \gamma-z u-1 о 5$, we need to posit a further step of derivation: first inclusion of the noun $u$-zi in a hypothetical ILC verb *a-zu-los "to have nausea (it)",

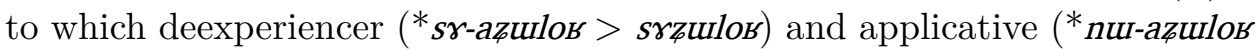
$>$ пъъииов) derivations are then applied.

\subsection{Light verb constructions}

Most denominal verbs compete with corresponding light verb constructions. In these constructions, the light verb (mostly $\beta z u$ "to do", Irt "throw" but also $t i$ "say" in some cases) receives TAM and person marking, while the noun is a regular object.

The following examples illustrate denominal vs. light verb constructions:

(i) thu-nu-rryo-a

AOR-DENOMINAL-SOng-1SG

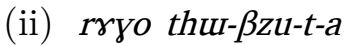

song AOR-do-PST-1SG

I sang. (elicitation, Chen Zhen)

(21) (i) nut-su-ndzupe-a

AOR-DENOMINAL-way.of.sitting-1SG

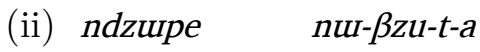

way.of.sitting AOR-do-PST-1SG

I sat (without crossing legs). (elicitation, Dpalcan)

In both examples, the first sentence has an intransitive denominal verb, while the second one has a light verb construction.

In Japhug, TAM marking relies on both verb stem alternation and directional prefixes. Except for movement verbs and some action verbs, which are compatible with all seven directions (up, down, upstream, downstream, east, west, undetermined), most verbs have a determined directional prefix. In the case of nurryo "sing" and sundzupe "sit" above, the aorist form of

${ }^{8}$ Other examples of applicative nur with a- initial verb stems include azuzu "to wrestle (vi)" (intrinsically reciprocal verb) $>$ * пш-ақшъи $>$ пrъшъu "to wrestle with (vt)". 
the lexical directional prefixes are respectively thur "downstream" and nu"towards west". 9

The same directional prefixes are found in both the denominal construction and the corresponding light verb constructions, showing that these two constructions are synchronically related to one another in a systematic way: In the light verb construction ndzupe nur- $\beta z u-t-a$, one finds the same nur"towards west" prefix as in the denominal nu-su-ndzupe-a "I sat without crossing legs".

Many denominal verbs (especially those in nu- and rü-) can be replaced by the corresponding light verb construction without significant change of meaning.

\subsection{Denominal prefixes and $I L C$}

The derivational prefixes which appear in ILC verbs, nu-, nr ушт, sur and $s \boldsymbol{r}$, all have corresponding homophonous denominal prefixes. One could indeed argue that the two groups are related.

It could further be proposed that some of the denominal and/or ILC prefixes have the same origin or even constitute synchronically the same markers as some verbal derivations, in particular the applicative nu- and the causative sur.

Yet, the phonetic resemblance between these prefixes alone is not enough to draw such a conclusion. In Japhug, the shape of prefixes is determined by various phonological constraints. With the exception of directional prefixes and one modal prefix, both derivational and inflectional prefixes never have consonant clusters, only have $/ \mathrm{a} /, / \mathrm{\gamma} /, / \mathrm{w} /$ as their main vowel, and contain only one of the following eleven consonants: $/ \mathrm{s} /,|z /,| \epsilon /, \mid z /, / \mathrm{z} /, / \mathrm{m} /, / \mathrm{n} /$, $|r /, / t /|, k /, \mid j /$ (the complete consonantal inventory of Japhug comprises 49 phonemes).

Therefore, we observe pervasive homophony among prefixes. For instance, nur-can be either denominal, applicative, spontaneous-autobenefactive, aorist directional "towards west", vertitive, third/second person plural prefix, as in the following examples:

1. rga "to like (vi)" > nur-rga "to like (vt)" (applicative)

2. rpu "to bump" > nu-rpu "to bump one's (body part)" (spontaneousautobenefactive)

3. $y i$ "to come" > nu- ye "come (towards west), aorist" (directional prefix)

4. $y i$ "to come" > nuI- $y i$ "to come back" (vertitive)

5. mto "to see" > nur-kur-mto "the one who sees them" (third/second person plural)

\footnotetext{
${ }^{9}$ These prefixes are simply glossed as "aorist" AOR, since the direction for these verbs is lexically determined.
} 
A similar list could be established with $\boldsymbol{s} \boldsymbol{\gamma}$-, which can occur as non-core nominalizer, deexperiencer, combination of causative and passive, deriving transitive de-ideophonic verbs, antipassive and denominal prefix. It is implausible that all these functions could have a common diachronic origin; their resemblance is (for some of them at least) fortuitous and due to the phonotactics of prefixes, which undergo different sound laws than regular vocabulary and neutralize many phonological distinctions (voicing, aspiration, main vowel etc).

Therefore, the question which needs to be addressed is whether the denominal and ILC derivational prefixes are only superficially similar, or whether they are related.

\section{Incorporation-Like Construction as Denominal Derivation}

The previous sections have described the formation of ILC and denominal verbs in Japhug, and we have observed that both groups of verbs present an important commonality: The presence of a series of homophonous derivational prefixes. The existence of these prefixes offers a clue as to the origin of ILC in Japhug, namely that it constitutes a special subtype of denominal verbs.

In this section, we first study nominal Noun-Verb compounds in Japhug and their relationship with ILC. Then, we discuss the question whether ILC constitutes incorporation.

\subsection{Noun-Verb composition in Japhug}

Aside from noun-noun composition as mentioned above, Japhug has a moderately productive process of nominal composition, in which a noun in the status constructus is combined with a verbal root to form a new noun:

Table 13: Examples of nominal noun-verb compounds

\begin{tabular}{|c|c|c|}
\hline Element 1 & Element 2 & compound noun \\
\hline tur-rcu"leather & gga "wear" (vt) & rcr-mbe-nga "beggar (the one \\
\hline jacket" & $u-m b e$ "old" & who wears old jackets" \\
\hline tşu "road" & $6 p^{h} \gamma t$ "patch" (vt) & $\begin{array}{l}t_{s} \gamma-\epsilon p^{h} \gamma t \text { "Plantago sp." } \\
\text { (a plant, lit. "road-patcher") }\end{array}$ \\
\hline$p^{h}$ on "bottle" & $s t i$ "fill, block" (vt) & $p^{h}$ on-sti "bottle stopper" \\
\hline$s i$ "wood" & $t_{c}^{h} a b$ "diminish" (vi) & sur-tc ${ }_{a b}^{h}$ "shrinking (of wood)" \\
\hline
\end{tabular}

The resulting compound can be either an agent noun, a patient noun or an action noun from the point of view of its semantics, without any formal marking. This kind of ambiguity is not normally found in Japhug nominalized verbs (or rather participles), which have different derivational 
prefixes depending of the semantic role of the relativized argument ( $k u$ - for $\mathrm{S} / \mathrm{A}, k \boldsymbol{r}$ - for $\mathrm{O} /$ action, $s \boldsymbol{r}$ - for non-core argument, tur for action etc).

For some examples such as "Plantago" or "bottle stopper", it is possible that the verbal root first underwent a process of nominalization with the prefix $t u-/ t r$ - before entering the compound: this prefix is regularly lost in composition. In most cases, there is no way to tell whether the derivation from a given noun and verb to the nominal compound $[\mathrm{NV}]_{n}$ followed the direct path in (i) or the indirect path in (ii): ${ }^{10}$

(i) $\mathrm{N}+\mathrm{V}>[\mathrm{NV}]_{n}$ composition

(ii) $t u \Psi^{(v>n)}+\mathrm{V}>\left[t u-\mathrm{V}^{(v>n)}\right]_{n}>[t u-\mathrm{V}]_{n}$ nominalization $\mathrm{N}+[t u r-\mathrm{V}]_{n}>[\mathrm{NV}]_{n}$ composition

For instance, the transitive verb $6 p^{h} \gamma t$ "to patch" has a derived noun $t \gamma-\epsilon p^{h} \gamma t$ "patch"; The plant name $t_{\varepsilon} \gamma-\epsilon p^{h} \gamma t$ could be either a compound of tsu "road" and $\varphi p^{h} \gamma t$ "to patch", or of $t s u$ and $t \gamma-\epsilon p^{h} \gamma t$. both "road patcher" and "road patch" would be fitting metaphors for this plant. The process of nominal compounding suppresses the nominalization prefix $t r$-, so that one never finds a from such as ${ }^{*} t s \gamma-t \gamma-\varphi p^{h} \gamma t$.

In some cases however, semantics can help to settle this issue. For instance, in rcr-mbe-nga "person who wears old jackets" can be glossed as:

\section{[tur-rcu uu-mbe] uu-ku-nga}

NEU-jacket 3SG-old 3SG-NMLZ:S/A-wear

Person who wears old jackets.

The first two syllables of the compound derive from the noun phrase tur-rcu $u$ umbe, and the whole compound has an Object-Verb structure.

Besides, if the last syllable in this compound - $n g a$ were derived from tur-nga "clothes", the nominalized form of gga "to wear", it should not have its attested meaning.

We can conclude in cases like this that the compound was directly derived from the verb root gga "wear" (path (i) in the example 22).

In any case, regardless of their exact diachronic origin, these noun-verb compounds can undergo denominal derivation like other nouns and be included in a verb stem. However, the resulting denominal verb, since it contains both a nominal and a verbal root, also seems to fit the definition of incorporation presented in section 2 .

\footnotetext{
${ }^{10}$ The conventions used in this article to describe the derivations are the following: capital $\mathrm{N}$ and $\mathrm{V}$ indicate nominal and verbal roots respectively, square brackets [] indicate word boundaries while lowercase $n$ and $v$ mark the part of speech (noun or verb) of a given word. Derivational affixes are written as $a f f x^{(v>n)}$, with the derivational function of the infix (here $\mathrm{v}>\mathrm{n}$ deverbal affix) indicated in superscript. Thus the derivation from a noun to a verb by a denominal affix is represented as $\mathrm{N}+$ affix $^{n>v}>\left[\mathrm{N}^{(n>v)}\right]_{v}>[\mathrm{N}]_{v}$
} 
The present section will show that all ILC verbs treated in section 3.3 constitute examples of precisely this construction.

Observe the following example, with the noun $q^{h}$ aru "a look back", built out of the noun $u-q^{h} u$ "behind" and the intransitive verb $r u$ "look":

he ERG faith AOR:3>3-put because look.back a.little even EMPH

mul-pa-lrt tee tr-ari juu-pu

NEG-AOR:3>3-throw COORD AOR:up-go[II] IPF-be

He had faith, as he did not look back at all, and went up. (Slobdpon 106)

$q^{h} a r u$ occurs here with the light verb $l \gamma t$ in a construction meaning "look back". An alternative construction to the light verb construction also exists, and appears in the same story a few sentences earlier:

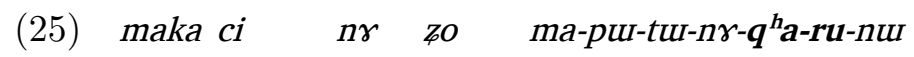

at.all a.little even EMPH NEG-IMP-2-DERIVATION-back-look-PL

ra ma pju-tul-rtrr-nut tee

N.PST:have.to because IPF-2-fall-PL COORD

Don't look back at all, otherwise you will fall. (Slobdpon 100)

It is clear from the above examples that the ILC verb $n \boldsymbol{r}-q^{h} a-r u$ "look back" is a denominal verb. ${ }^{11}$ Like other denominal verbs, it is interchangeable with a light verb construction, and both constructions share the same lexical directional prefix pur "down" (the form pa- occurs in aorist $3>3$ forms of transitive verbs only, so that the ILC verb, being intransitive, has the basic form pur-).

It can be shown that many of the ILC verbs in Japhug belong to the same type as $n \boldsymbol{r} \boldsymbol{q}^{h}$ aru "to look back". We can conclude that the observed similarity of the denominal prefixes and the derivational prefixes found in ILC verbs is not fortuitous: they are really the same morphemes, and ILC is a subtype of denominal derivation.

The development of ILC in Japhug can therefore be described as follows:

(26) (i) Creation of a noun + verb nominal compound: $\mathrm{N}+\mathrm{V}>[\mathrm{NV}]_{n}$

(ii) Denominal derivation of this compound: $\operatorname{affix}^{(n>v)}+[\mathrm{NV}]_{n}>$ $\left[[\mathrm{NV}]_{n}^{(n>v)}\right]_{v}$

Another possible path of derivation to interpret Japhug data would be:

\footnotetext{
${ }^{11}$ Note that the adverb $c i$ "one, a little" is not a stranded element: in the first sentence $q^{h}$ aru "a look back" and $c i$ do not form a constituent. $c i$ "one, a little" is indeed an indefinite nominal marker in some cases, but its use as a phrasal modifier is well attested, see for instance example 19 of the present article.
} 
(27) (i) Denominal derivation: affix ${ }^{(n>v)}+\mathrm{N}>\left[\mathrm{N}^{(n>v)}\right]>[\mathrm{N}]_{v}$

(ii) Composition of the denominal verb with a normal verb $[\mathrm{N}]_{v}+$ $\mathrm{V}>[\mathrm{NV}]_{v}$

However, solution (27) would leave $[\mathrm{NV}]_{v}$ nominal compounds such as $q^{h}$ aru "look back" above unexplained, and is contradicted by the fact that $[\mathrm{VV}]_{v}$ compounds are relatively rare in Japhug. This grammatical pathway may however have existed in other language families, though no examples are known to the author. Similar phenomena in other languages will be discussed in section 6 .

The following table shows the correspondences between Japhug ILC verbs and nominal forms: 
Table 14: ILC verbs and compound nouns

\begin{tabular}{|c|c|c|c|}
\hline compound noun & meaning & ILC verb & meaning \\
\hline $\mathrm{X}$ & & $a-k \gamma-m t 6 O B$ & having a pointed head \\
\hline$c^{h} \gamma t s_{i}$ & alcohol drinking & $\gamma u-c^{h} \gamma-t s_{i}$ & drink alcohol \\
\hline $\operatorname{cup}^{h}$ uut & clearing the stones & $\gamma u-c u-p^{h} u t$ & take out stones (out of the field) \\
\hline glutert & taking out the dung & gut-ylu-tçrt & take out dung (out of the stable \\
\hline yndzr $\beta$ ta & fire (devastating) & & clear (fields) with fire \\
\hline$k^{h} u t s^{h} O B$ & hunting (with dogs) & $\gamma u-\boldsymbol{k}^{h} u-t s^{h} O B$ & turn the dog loose on \\
\hline pqawtsuffsob & money earning & yu-pcawtsut-fSOS & earn money \\
\hline rfunfsos & earning of riches & gu-rf孔U-fSOB & earn riches \\
\hline supp ${ }^{h}$ uut & tree felling & gut-sut-phut & cut wood (to make firewood) \\
\hline$t s^{h} \gamma t s_{i}^{h}$ & tea drinking & $\gamma u-t \boldsymbol{S}^{h_{\gamma}-t S^{h}}$ & have tea \\
\hline$t$ tsrmts ${ }^{h} i$ & leading & $\gamma u-t_{S} \gamma-m t s^{h_{i}}$ & lead the way \\
\hline $\mathrm{X}$ & & $n \gamma-j l \gamma \beta$-sqa & cook with steam (vt) \\
\hline$k r t \epsilon^{h} u$ & headbutt & $n \gamma-k \gamma-t \epsilon^{h} u$ & hit with the head (vt) \\
\hline zgrut $^{h} u$ & nudge (n) & nuI-zgruu-tg ${ }^{h} u I$ & nudge (vt) \\
\hline $\mathrm{X}$ & & $n \gamma-m p^{h} r u-z a$ & do after after the other \\
\hline trp $p^{h}$ uxtsui & clod-breaking (vt) & $n \gamma-p^{h} \boldsymbol{u}-x t s u U$ & break clods of earth \\
\hline $\mathrm{X}$ & & $n \gamma-q a-z a$ & start from the beginning (vt) \\
\hline$q^{h_{a} a r u}$ & look back (n) & $n \gamma-q^{h} a-r u$ & look back \\
\hline $\mathrm{X}$ & & $n \gamma-\boldsymbol{q}^{h} \gamma-\eta g a$ & to wear on the back \\
\hline $\mathrm{X}$ & & $n \gamma-z u-l o s$ & have nausea \\
\hline jlrlry & yak herding & 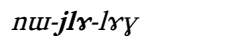 & herd hybrid yaks \\
\hline jlrmts ${ }^{h} i$ & yak leading & $n u-j \mid \gamma-m t s^{h} i$ & lead hybrid yaks \\
\hline $\mathrm{X}$ & & nu-mbrr-pu & ride $(\mathrm{vl})$ \\
\hline mbrrrfuу & horse race & nuu-mbrr-rfury & gallop \\
\hline $\mathrm{X}$ & & nu-ngr-tso & pay back one's debt \\
\hline rfurryom & & пит-гуu-rпom & envy people's wealth \\
\hline $\mathrm{X}$ & & пuт-prm- $k^{h} e$ & skinny \\
\hline $\mathrm{X}$ & & пu-рлrm-su & plump \\
\hline равlгy & pig herding & 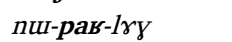 & herd pigs \\
\hline $\begin{array}{l}p^{h} \text { abjzrl } \\
?\end{array}$ & laying on the side & $\begin{array}{l}\text { nut-p } \boldsymbol{p}^{h} \text { as-jrl } \\
\text { nuI- } q^{h} \gamma \text {-stul-stu }\end{array}$ & $\begin{array}{l}\text { lay on the side } \\
\text { back up }\end{array}$ \\
\hline rmrkro & household splitting & пu-rmr-kro & split the household \\
\hline rmrmbe & moulting & nus-rmr-mbe & moult \\
\hline sпшлав & harm (n) & пит-snu-лав & harm \\
\hline zruyru & louse-picking & пu-zrury-ru & look for lice \\
\hline tsrarsti & road-blocking & $n u-t_{\boldsymbol{S}} \boldsymbol{\gamma}-q \gamma-s t i$ & block the way \\
\hline $\mathrm{X}$ & & sr-mbru-pgut & be detestable \\
\hline $\mathrm{X}$ & & $s \gamma-z \boldsymbol{u}-l o b$ & be disgusting \\
\hline
\end{tabular}

The compound action noun from which ILC verbs are derived can always occur in a light verb construction (like $q^{h}$ aru above). We thus observe three competing constructions, as in the following examples:
(28)
(i) cut-p $p^{h} u t t$
nut- $\beta z u-t-a$
stone-clearing AOR-do-PST-1SG
I cleared stones (from the field).
(ii) nut-yu-cur- $p^{h} u t-a$
AOR-DERIVATION-stone-take.out-1SG
I cleared stones (from the field). 
(iii) cuu nut-p $p^{h} u t-a$

stone AOR-take.out-1SG

I cleared the stones (from the field). (elicitation, Chen Zhen)

Semantically, the three constructions are not entirely equivalent: light verb constructions (i) are used to insist on an action taking a long time, or occurring many times, and could be glossed in English as "I devoted myself to clearing the stones." The incorporating and the analytic constructions are almost identical according to native speakers, though only (iii) can be used if the object is referential. In the pairs of examples $16 / 17$ and 24 / 25 above, we saw that the ILC verb appeared first in the text, followed by the analytic construction or the light verb construction a few sentences later: these examples suggest that ILC is favoured in the first mention of an event, though more such examples from spontaneous texts are needed. Unfortunately however, the rarity of these examples in natural texts make it difficult to study the pragmatic differences between the three constructions.

These can be elicited for all verbs in table 14 which have a corresponding compound noun.

Aside from occurring in light verb constructions with $\beta z u$ "do" or $l \gamma t$ "throw", the noun-verb nominal compounds also appear in sentences such as the following:

(29) jndzrßta pur-tu

fire PST.IPF-be.there

There was a fire. (elicitation, Chen Zhen)

(30) $k^{h}$ uts ${ }^{h} O B \quad$ rga

hunting.with.dogs N.PST:like

He likes hunting with dogs. (elicitation, Chen Zhen)

As table 14, in some cases no corresponding independent noun exists. There examples include:

- All ILC verbs derived from noun-stative verb collocations (such as the example "to have nausea").

- Some ILC transitive verbs ( $\operatorname{such}$ as $n \boldsymbol{\gamma}-q^{h} \boldsymbol{\gamma}$-nga "to wear on one's back")

- The stative $a-k r-m t$ or "having a pointed head", which is the only example of ILC whose derivational prefix is not denominal.

It seems reasonable to hypothesize that all examples from table 14 originated from noun-verb compounds, even if these compounds are not present in the variety of Japhug studied here. A similar study in other Rgyalrong languages or even other dialects of Japhug might yield different results, and could be instructive to determine the relative antiquity of ILC verbs. 


\subsection{Is there incorporation in Japhug?}

The ILC is somehow a paradox: This construction seems to fulfil the definition of incorporation presented in section 2 , and yet it is also clearly almost always a special category of denominal verbs.

It constitutes a phenomenon quite distinct from prototypical incorporation, as exemplified by Nahuatl (Launey 1980: 165-166):

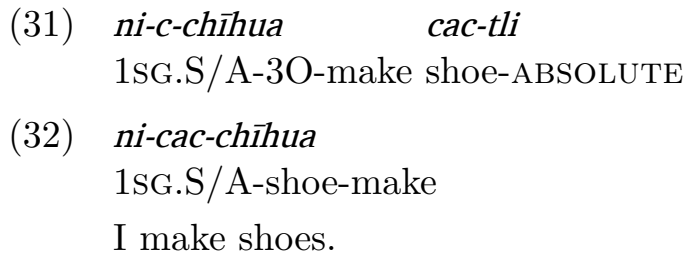

In Nahuatl, incorporating verbs such ni-cac-chīhua differ from the Japhug ILC verbs in that no additional derivational affix appears alongside the nominal and the verbal root. ${ }^{12}$ Nahuatl has denominal verbs that are formed by the addition of the suffix - $t i$ to the nominal stem, for instance pochtēca"seller" > pochtēca-ti "to do business", and one cannot convert a nominal root into a verb without addition of that suffix: it is therefore impossible to argue that verbs such as ni-cac-chīhua derive from a noun *cac-chīhua that was verbalized by zero-derivation. In Nahuatl, incorporation is a one-step process, by which the noun is integrated into the verbal enlarged stem to form a single word. In our notation, Nahuatl-type incorporation can be represented as simply: $\mathrm{N}+\mathrm{V}>[\mathrm{NV}]_{v}$.

In Japhug, on the contrary, ILC is a three-step process:

1. Verb nominalization.

2. Compounding of the nominalized verb with a nominal root to form a nominal noun-verb compound (semantically an ACTION NOUN in all cases); nominalization markers are lost.

3. Derivation of that nominal compound into a verb using a denominal prefix. Noun-verb compounding is therefore embedded within the denominal derivation, unlike in Nahuatl where it is a one-stage process.

The ILC $\left[[\mathrm{NV}]_{n}^{(n>v)}\right]_{v}$ could only be reinterpreted as $[\mathrm{NV}]_{v}$ (incorporational construction) in the case of zero-derivation, or if the derivational prefixes disappeared due to phonetic changes; however, neither is the case in Japhug.

\footnotetext{
${ }^{12}$ Note however that in some language families with constructions generally analysed as incorporation, such as Algonquian, we find a derivational affix in most incorporating verbs, see section 2 of the present article. On the origin of the incorporational construction in Algonquian, see Garrett (2004).
} 
Therefore, from the point of view of morphological structure, most ILC verbs cannot be analysed as incorporating verbs. Nevertheless, from a functional point of view, it is clear that ILC presents at least three properties common to incorporating constructions. First, ILC verbs are verbal nounverb compounds that fulfil the definition given in section 2. Second, the nominal element of ILC is always non-referential. Third, we observe the same constraint on ILC nominal elements as on incorporated nouns: S, O and adjunct nominal elements can appear in ILC, but not A.

ILC and related forms in Japhug can be divided into five distinct categories depending on the nature of the nominal element. We now examine whether each of these categories a) constitutes prototypical incorporation b) constitutes a noun-verb verbal compound.

The first category includes most ILC verbs. In this type, the nominal element is a plain underived noun, such as cur "stone" in ru-cut-pht "to take out stones (out of the field)". These verbs, as mentioned above, cannot be analysed as incorporation.

The second category is exemplified by only one verb, $a-k \gamma-m t c o s$ "having a pointed head". Unlike other ILC verbs, it lacks a denominal prefix, as the element $a$ is part of the original verb amt6os "pointed". Although this last verb derives historically from the stative verb $m t \epsilon o s$ "sharp" by addition of $a$, the prefix $a$ - here is not a derivational element (it is unrelated to the homophonous passive a- prefix) and it is not analysable synchronically. In $a-k \gamma-m t \epsilon о в$, the noun is synchronically incorporated within the verbal stem. This example, unlike verbs of the first category, constitutes unambiguous incorporation.

The third category contains two verbs nu-ngr-tso "to pay one's debt" and nu-rmr-kro "to split the household". In these two examples, the nominal elements originate from deverbal nouns, respectively tur-nja "debt" and turrma "household", which themselves come from the verbs nga "to owe" and rma "to stay at a place". The status constructus stems -ngr-and -rm are formally ambiguous: they could originate either from the verb or from the derived nouns (since the deverbal prefix $t u$ - is lost during the status constructus formation). Only the meaning allows us to determine that these elements originate from nouns and not from verbs. ${ }^{13}$

Like verbs of the first category, these two verbs cannot be considered as instances of prototypical incorporation, but they do not constitute real noun-verb compounds either, due to the formal ambiguity of the nominal elements.

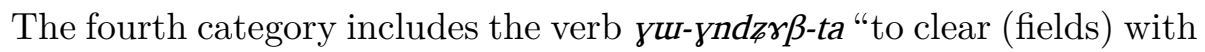

\footnotetext{
${ }^{13}$ Note that verb-verb compounds also exist in Japhug: from jos "to raise" and $\beta z u r r$ "to move" one derives the noun јовßzurr "putting in order, tidying up" hence the verb гrjosßzur "to tidy up".
} 
fire". In this ILC verb, the nominal element $\operatorname{ynd}_{z \gamma} \beta$ "fire" is a deverbal noun as in third category ILC verbs. However, it differs from these verbs in that yndzr $\beta$ "fire" is a fossilized formation deriving from $n d_{z r} \beta$ "to burn" by the irregular prefix $\gamma^{-}$. Since $\gamma^{n} d_{z} \gamma \beta$ "fire" is not a synchronically transparent deverbal noun from $n d_{z \gamma} \beta$ "to burn", and since a trace of the derivation is preserved within the compound, there is no ambiguity as to the nominal status of this element.

The fifth category is the aberrant verb krtupa "to speak" mentioned in section 3. This verb resembles $у ш u-y n d z \gamma \beta-t a$ "to clear (fields) with fire" in that it includes a deverbal noun preserving its derivation prefix. The element $k r t u$ - is the status constructus of $k r-t i$ "things that are said, niggling" which derives from $t i$ "to say" by addition of the regular $k \boldsymbol{k}$-participle prefix. This verb, unlike other ILC verbs, lacks any derivation prefix, and cannot be analysed as denominal derivation neither synchronically nor even diachronically. Therefore, just as $a-k \gamma$-mtcos "having a pointed head", it can be analysed as incorporation.

The following table summarizes the previous discussion:

Table 15: Subtypes of ILC verbs

\begin{tabular}{|c|c|c|c|}
\hline type & example & Incorporation & NV compound \\
\hline 1 & $\gamma_{u-c u-} p^{h} u t$ "to take out stones (out of the field)" & $\mathrm{N}$ & $\mathrm{Y}$ \\
\hline 2 & $a-k \gamma-m t c o s$ "having a pointed head" & $\mathrm{Y}$ & $\mathrm{Y}$ \\
\hline 3 & nu-nnr-tso "to pay one's debt" & $\mathrm{N}$ & $\mathrm{N}$ \\
\hline 4 & $\gamma u-\gamma n d z \gamma \beta-t a$ "to clear (fields) with fire" & $\mathrm{N}$ & $\mathrm{Y}$ \\
\hline 5 & krtur-pa "to speak" & $\mathrm{Y}$ & $\mathrm{Y}$ \\
\hline
\end{tabular}

In conclusion, there are really only two incorporating verbs in Japhug: krtupa "to speak" and akrmtcos "having a pointed head", but most ILC verbs (except those of category 3 ) constitute noun-verb verbal compounds, and are functionally similar to incorporating verbs.

\section{Typological perspectives}

In the previous section, we have shown that most Japhug ILC verbs do not constitute prototypical incorporation, but rather a denominal construction whose syntactic functions resemble incorporation.

In this section, we will present other types of ILC in various languages, and show that ILC can develop into incorporation.

\subsection{Incorporation-like construction in other languages}

Incorporation-like constructions are not restricted to Japhug Rgyalrong. Similar constructions can be found in Ancient Greek and in familiar Germanic languages such as German and English.

In Ancient Greek, we find a few denominal verbs which can be analyzed as a type of ILC (see Benveniste 1966): 
(33)

(i) oiko-ঠó $\mu-о 5$

house-build-NOM.SG.MASC

"house builder, architect"

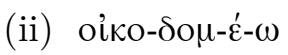

house-build-DENOMINAL-1SG

"to build a house, erect a building"

Compound nouns of type (i) include a noun (here oîkos "house") and the

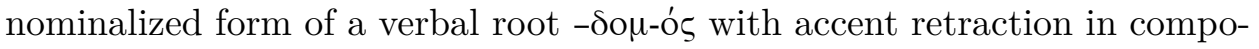
sition (here from the -o- grade of the root $* \mathrm{demh}_{2}$, the corresponding verb

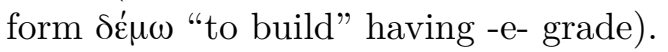

Denominal verbs of type (ii) are derived from (i) by addition of a denominal suffix $-\dot{\varepsilon}-;$ this is the productive way of forming denominal verbs in Greek (cf $\pi o ́ \lambda \varepsilon \mu-o \varsigma$ "war" > $\pi 0 \lambda \varepsilon \mu-\varepsilon-\omega$ "to be at war").

The Greek construction differs from Japhug ILC in three ways. First, the nominal compounds in (i) are always agent nouns, never abstract nouns as in Japhug. Second, the verb $>$ noun derivation by ablaut ( $\delta \varepsilon \dot{\mu} \mu$ "to build" > - $>0 \mu$-ós) was not fully productive by the fifth century BC (when

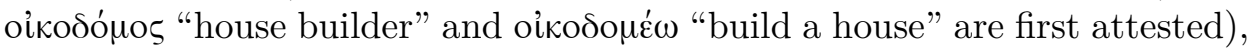
unlike derivation by tur- in Japhug. Third, the second element of the compounds with -o- vocalism is always formally different from the stem of the corresponding verb (with -e- vocalism), unlike Japhug where they are almost always identical (except for snom "to envy" > nurfurryom "to envy people's wealth"). Thus, while the derivation formula for Japhug ILC is $\left[[\mathrm{NV}]_{n}^{(n>v)}\right]_{v}$, that of Greek oikooo $\mu \varepsilon \dot{\omega} \omega$ "build a house" is rather $\left[\left[\mathrm{N}\left[\mathrm{V}^{v>n}\right]_{n}\right]_{n}^{(n>v)}\right]_{v}$.

In German, we find the interesting case of the verb staub-saug-en "to hoover". ${ }^{14}$ This verb is formed of two elements related to the noun Staub "dust" and the verb saug-en "to suck". Since it can be conjugated in all finite forms, both of its constituting elements can appear independently, and it constitutes a unique morphological and phonological word, it would appear to be an example of incorporation according to our definition. This verb is ambitransitive, and can occur with a patient in some cases:

(34) ich staub-saug-e

I dust-suck-1sG.PRESENT

I do the hoovering.

ich staub-saug-e den Boden
I dust-suck-1SG.PRESENT ART.M.SG.ACC floor
I am hoovering the floor.

${ }^{14}$ I owe this example and the related discussion to Johanna Mattissen. 


\footnotetext{
${ }^{15}$ Scores of similar examples, involving - hunt or -pick as a second element, but also verbs such as horse-race, can be found in colloquial internet texts.
}

Note that a competing form with the nominal element occurring separately also exists:
Staub in 36 is clearly not an object, as it cannot receive an article, and in any case this second construction does not constitute incorporation. This kind of discontinuous structure is not surprising in German, where many prefixal elements can appear separated from the verb stem in finite forms (eg. Ich mache die Tür auf "I open the door" from the verb auf-machen "to open").

However, the verb staubsaugen "to hoover", as pointed out by Mattissen, must have been built from the noun Staubsauger "vacuum cleaner" by backformation, since the activity could not have existed before the invention of this machine. In other words, compounding occurs within another derivation in this case as in Japhug.

The German verb staubsaugen differs however in three ways from the Japhug ILC verbs. First, as mentioned above, it is built by backformation, not by denominal derivation. Second, the base noun is an instrument, not a action noun. Third, there is no derivational element comparable to the Japhug denominal prefixes $y u-$, nu- etc in this German verb.

This shows that the phenomena observed in Japhug are but a particular case of all theoretically possible forms of incorporation-like constructions. Also, in the case of German, ILC is formally indistinguishable from genuine incorporation; only knowledge of the derivational history of the word allows us to determine that it does not constitutes a direct $\mathrm{N}+\mathrm{V}$ verbal compound.

In English, we find ambiguous verbal compounds that can be interpreted as incorporation, due to the pervasive presence of zero-derivation (both from noun to verb and from verb to noun). For instance, in non-standard varieties of English, one finds sentences such as the following (taken from the internet): ${ }^{15}$

(37) I duck hunted Lake Ophelia for years.

The verb "to duck-hunt" exemplified by this example apparently constitutes non-saturating nominal incorporation. It must have originated from the compound noun duck-hunt by zero-derivation, and thus would seem to be a verbalized Noun-Noun compound.However, since the verb and the noun hunt in English are homophonous, there is synchronically no evidence that the root hunt in the verb to duck-hunt is nominal rather than verbal. Here again 
in English we observe a third kind of incorporation-like construction, that came into being due to the pervasive noun - verb homophonous pairs. As in the case of the German backformation and unlike Japhug, the absence of formal derivational markers allwos the English construction to be reanalysed as incorporation in spite of being historically a denominal construction.

The development path described above is by no means restricted to English. Creissels \& Sambou (manuscript: 279) have proposed an interpretation of incorporation constructions in the Mandinka language along the same lines: "Verbal compounds [i.e. incorporating verbs], rather than being directly formed after corresponding syntactic constructions, originate from nominal compounds later converted to verbs". ${ }^{16}$ It is likely that such a development is rather common in languages like English and Mandinka, in which it is possible to convert nouns into verbs without overt morphological marking.

Incorporation-like constructions include three types of attested derivations exemplified by Japhug/Greek, German and English/Mandinka respectively:

(i) $[\mathrm{NV}]_{n}+\operatorname{affix}^{(n>v)}>\left[[\mathrm{NV}]_{n}^{(n>v)}\right]_{v}\left(>[\mathrm{NV}]_{v}\right)$

Denominal derivation of a noun-verb nominal compound (Japhug, Greek). Notice that the last stage of the derivation, namely the reanalysis of the ILC as incorporation, is blocked due to the presence of overt denominal marking in these languages. Greek differs from Japhug in that the compound noun from which the ILC is derived already contains an unambiguous verb > noun derivation: $\left[\left[\mathrm{N}\left[\mathrm{V}^{v>n}\right]_{n}\right]_{n}^{(n>v)}\right]_{v}$; reanalysis as genuine incorporation is even more difficult.

(ii) $\left[[\mathrm{NV}]_{v}^{(v>n)}\right]_{n}-\operatorname{affix}^{(v>n)}>[\mathrm{NV}]_{v}$

Backformation from a nominal compound including a nominal and a verbal root (German)

(iii) $[\mathrm{NN}]_{n}>[\mathrm{NN}]_{v}>[\mathrm{NV}]_{v}$ reanalysis as $[\mathrm{NV}]_{v}$ due to homophony between noun and verb (English)

These phenomena are not commonly analysed as incorporation, due to the fact that the order of derivation is distinct from "classical" incorporating languages such as Nahuatl. However, speakers are not usually conscious of the derivational history of the constructions they use, and ambiguous forms

\footnotetext{
${ }^{16}$ [les] composés verbaux, plutôt que d'être formés directement à partir des constructions syntaxiques correspondantes, proviennent de composés nominaux ultérieurement convertis en verbes"
} 
can be reanalysed; the synchronic head-complement structure of a compound does not necessarily reflect the historical one.

\subsection{Lavrung}

Lavrung, a language closely related to Japhug (both belong to the Rgyalrongic subbranch of Sino-Tibetan, see Sun 2000), presents a similar system of denominal derivation, and there are a few examples of ILC in the published data on this language.

\subsubsection{Denominal derivation in Lavrung}

Denominal derivation in Lavrung, as in Japhug, is based on a series of prefixes, but unlike Japhug, it also allows zero-derivation (Huang 2007: $145-6):{ }^{17}$

Table 16: Denominal derivation in Lavrung

\begin{tabular}{|c|c|c|c|}
\hline $\begin{array}{l}\text { Base noun } \\
\text { day } \\
\text { lva } \\
\text { lva } \\
\text { svə } \\
\text { phray }^{55} \\
\text { srdzy }^{55}\end{array}$ & $\begin{array}{l}\text { Meaning } \\
\text { poison } \\
\text { shoulder } \\
\text { pus } \\
\text { sieve } \\
\text { sprout }\end{array}$ & $\begin{array}{l}\text { Verb } \\
n-d a \gamma^{55} \\
n-l v a \gamma^{55} \\
n-s v \partial^{53} \\
s-p h r a \gamma^{55} \\
\text { - }<\text { - }>\text { rdzyə }\end{array}$ & $\begin{array}{l}\text { Meaning } \\
\text { to be poisoned } \\
\text { to bear on the shoulder } \\
\text { to suppurate } \\
\text { to sieve } \\
\text { to sprout }\end{array}$ \\
\hline $\begin{array}{l}x t s \partial m^{53} \\
z g l e^{55} \\
\chi t 6 o^{53}\end{array}$ & $\begin{array}{l}\text { mortar } \\
\text { bolt } \\
\text { leprosy }\end{array}$ & $\begin{array}{l}\text { xtsəm } \\
\text { (nc-)zgle } \\
(\mathrm{ka}-) \chi \mathrm{tco}^{55}\end{array}$ & $\begin{array}{l}\text { to husk with mortar and pestle } \\
\text { to bolt (the door) } \\
\text { to get leprosy }\end{array}$ \\
\hline
\end{tabular}

The Lavrung prefixes n-, s- and f-/v- clearly corresponds to Japhug nu-

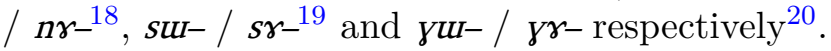

The absence of derivational prefixes in the last three examples can be interpreted in three ways.

1. The derivation took place from verb to noun, not from noun to verb.

2. There used to be denominal zero-derivation in proto-Rgyalrongic, the common ancestor of Lavrung and Japhug, and this derivation was only preserved in Lavrung.

3. The Lavrung verbs lost their denominal prefix in these examples.

\footnotetext{
${ }^{17}$ The syllables between brackets are the aorist prefixes.

${ }^{18}$ We find in Japhug denominal verbs that are partially parallel to the Lavrung ones:

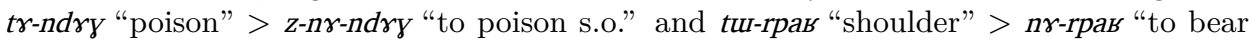
on the shoulder"

${ }^{19}$ Example semantically parallel to Japhug curyra "sieve" > su-

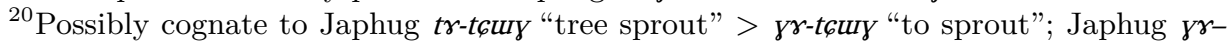
is the regular outcome of proto-Japhug ${ }^{*} w \boldsymbol{E}$-.
} 
The first hypothesis can be ruled out: the only forms of nominalization reported in Huang (2007) involve the addition of suffixes; there are no examples of affixless nominalization in this language. The second hypothesis is unlikely, given the complete absence of denominal zero-derivation in Japhug. If this process had been productive, we would expect at least some traces of it in Japhug. We will now examine the third hypothesis in more detail.

Japhug CV prefixes generally correspond to simple consonant prefixes in Lavrung. Since these prefixes present a vowel contrast (u or $\gamma$ ) in Japhug while this contrast is lost in Lavrung, it is clear that Lavrung is innovative and underwent syncope. ${ }^{21}$

The massive syncope affecting Lavrung prefixes resulted in a proliferation of exceedingly complex consonant clusters. The prefixes have lost productivity (unlike Japhug, they cannot be applied to recent Chinese loanwords) and often undergo metathesis with the initial clusters (as in $b<v>r d z y \partial^{55}$ " to sprout" in the table above).

However, some restrictions on the prefixes exist. In particular, con-

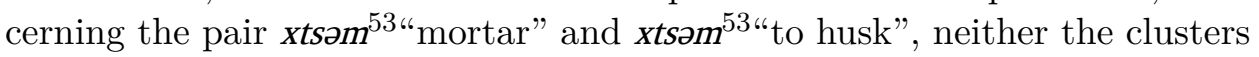
${ }^{*}$ fxts,$- x f t s-{ }^{*}$ yxts - nor ${ }^{*} x n t s-$ exist in Lavrung, so that the derivational prefixes $n$ - and $v^{-}$, even if originally present in the verb $x t s ə m^{53}$ "to husk" disappeared for purely phonetic reasons. ${ }^{22}$

Prefix attrition is a general feature of Lavrung: in this language, many prefixes still productive in Japhug only exist as traces. For instance, there is no prefix corresponding to the Japhug nominalization prefix ku- in Lavrung, but traces are found in fossilized forms such as ydzav "fire", cognate of Japhug $\gamma^{n} d_{z \gamma} \beta$ "fire" (see the preceding section for the etymology of this noun). Many Japhug prefixes, such as the second person tu- or the irrealis $a^{-}$, have no equivalent in Lavrung, but can be conjectured to have been lost in this language. ${ }^{23}$

\subsubsection{ILC in Lavrung}

The presence of incorporation or an incorporation-like construction in Lavrung has never been specifically mentioned, but in Huang (2007) we find two clear examples of such constructions.

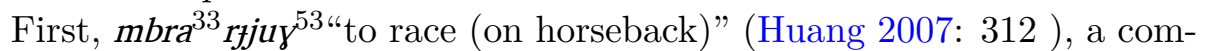

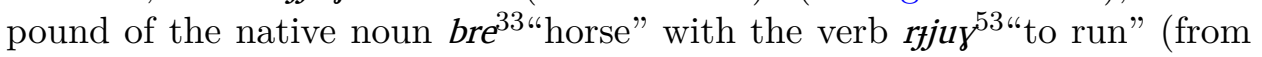
Tibetan rgjug "to run"). The noun in status constructus (with $-\boldsymbol{e}>-\boldsymbol{a}$

\footnotetext{
${ }^{21}$ If instead one assumed that Japhug is innovative and underwent general vowel anaptyxis in prefixes, the origin of the vowel contrast would not be explainable.

${ }^{22}$ Similar phenomena have been documented in the related language Horpa by Sun (2007).

${ }^{23}$ The second person prefix $t u-$ in Japhug is unlikely to be be a recent innovation, as argued in Jacques (2012a).
} 
vowel alternation) appears between the verb root and denominal prefix $m$ (allomorph of $n^{-}$). The aorist form of this verb is:

(39) $n \varepsilon^{33}-m-b r a^{33}-r f j u \gamma^{55}$

AOR-DERIVATION-horse-run

The presence of the aorist prefix before the noun dispels any doubt that this compound is one morphological word and not a noun-verb collocation.

This example is identical in structure to Japhug nu-mbrr-rfury "to gallop" mentioned above, and one finds a one-one correspondence in structure:

$\begin{array}{ccc}m- & \text { bra }^{33}- & \text { rfjur }^{53} \\ \text { nut } & \text { mbrr } & \text { rfur } \\ \text { rivation } & \text { horse (status constructus) } & \text { run }\end{array}$

derivation horse (status constructus) run
Although this example is no proof that the compound "race on horseback" can be reconstructed to proto-Rgyalrongic (both verbs could have been constructed independently from the same elements), it proves that the ILC existed in the proto-language.

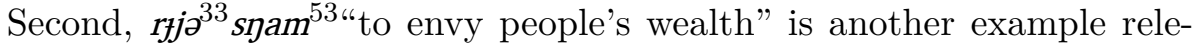
vant to our discussion (quoted from Huang 2007: 321). This verb originates from $r_{f j} \partial^{33}$ "property, goods, wealth" (a borrowing from Tibetan $\mathrm{rg}^{j} u$ "fortune") and the verb rnom "to be greedy for, to lust for". The aorist form of this verb is:

(40) $n \varepsilon^{55}-r f j \partial^{55}-$ s $^{5} \mathrm{~m}^{55}$

AOR-wealth-be.greedy

Here again, the noun appears between the aorist prefix and the verb root, and the compound constitutes a single morphological word. This verb clearly has the same structure as Japhug nut-rfur-ryom "to envy people's wealth",

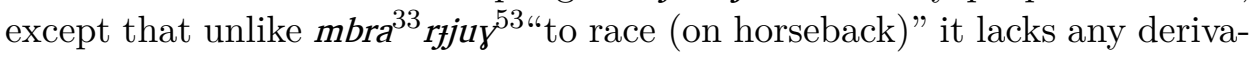
tional prefix, and we can analyse it as an incorporational construction. However, given the rarity of incorporation in Japhug, and the fact that derivational prefixes (the only distinguishing feature of incorporation and ILC) tend to disappear in Lavrung, it is unlikely that this verb arose as a result of direct noun-verb compounding in Lavrung. A more likely hypothesis is that this incorporating verb is an ancient ILC verb whose prefix disappeared for phonotactic reasons; neither groups of type ${ }^{*} n r C$ - nor of the type ${ }^{*} r n C$ (where $\mathrm{C}$ stands for any consonant) are attested in Lavrung. It is therefore legitimate to suppose a form ${ }^{*} n$-rfə-snam in pre-Lavrung similar to Japhug nu-rfu-rnom, which simplified to the attested $r f j \partial^{55}$-snam ${ }^{55}$ due to the phonological constraint on having consonant clusters containing both $/ \mathrm{n} /$ and $/ \mathrm{r}$ / before another consonant.

The loss of any overt marking of denominal derivation in $r f j \partial^{55}-$ spam $^{55}$, combined with the absence of any action noun compound such as Japhug rfurnom "envying people's wealth" as such compounds do not exist in Lavrung, 
makes it possible to analyze this verb as incorporation synchronically. Thus, it exemplifies a grammaticalization pathway similar to that observed in English and German:

\section{(41) INCORPORATION-LIKE CONSTRUCTION > INCORPORATION}

A more exhaustive study of incorporating verbs in Lavrung will not be possible without complementary fieldwork on this language, but this section has shown that both ILC and incorporation are attested in spite of the limited published corpus, ${ }^{24}$ and that incorporation is likely to originate from ILC in this language.

\section{Conclusion}

The data presented in the previous sections from Japhug and other languages illustrate a new path of development:

\section{(42) NOUN-VERB ACTION NOUN COMPOUND + DENOMINAL DERIVATION} $>$ INCORPORATION-LIKE CONSTRUCTION $>$ INCORPORATION

The Japhug ILC is an intermediate stage on this development path; it can become incorporation only when the denominal derivation marker either 1) is absent due to zero-derivation (as in English and Mandinka) 2) disappears due to phonological attrition (as in Lavrung) 3) becomes restricted to nounverb compounds and ceases to be a denominal marker synchronically.

The noun-verb compounds themselves can have the following origin:

\section{(43) NOUN + NOMINALIZED VERB > NOUN-VERB NOMINAL COMPOUND}

Alternatively, they may, as in the case of English, be intrinsically ambiguous noun-noun compounds forms that can be reinterpreted as noun-verb compounds due to noun-verb homophony.

The only previously known origin of incorporation, noun coalescence, can explain most of the incorporating structures observed in the world's languages. Even in languages such as Iroquoian, where incorporated nouns appear between the inflectional prefixes and the root (Mithun 2000), one could argue that incorporated nouns were originally free nouns, cliticized to

\footnotetext{
${ }^{24}$ Lai Yunfan, a student working on the Wobzi dialect of Lavrung (on which see Lai 2012)

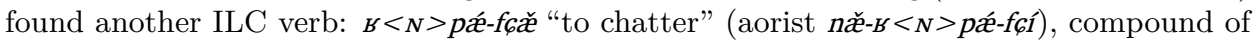
$f_{\varphi} \hat{x}$ (aorist $\left.n u-f_{\varphi} \hat{1}\right)$ "to tell" and $\chi p i^{\prime}$ "story" with the denominal marker $N^{-}$(allomorph of $n-$ ) appearing infixed in the nominal element. He also reports the absence of a corresponding noun-verb action noun compound ${ }^{*} \chi p æ-f \epsilon i$. Further fieldwork will certainly reveal other such verbs.
} 
the verb, that progressively coalesced with it. In the first stage of development, they would always appear as the outermost morpheme of the verbal word (as in Limbu), but progressively get closer to the verbal root by way of externalization of inflection (Haspelmath 1993).

This article however shows that incorporation does not necessarily originate from noun-verb coalescence, but could be a special development of denominal derivation in at least some languages.

In order to avoid the cumbersome expression "Incorporation-like construction", we suggest the use of the term "indirect incorporation" in future studies to refer to the phenomena observed in Japhug, English and German studied in this article.

Genuine incorporation, such as what is observed in Nahuatl or in the Japhug verb akrmtcos "having a pointed head", can be called "direct incorporation" to avoid confusion.

\section{References}

Aikhenvald, A. (2007). Typological distinctions in word-formation. In Language Typology and Syntactic Description, Volume III: Grammatical Categories and the Lexicon (pp. 1-64). Cambridge: Cambridge University Press.

Baker, M. (2009). Is head movement still needed for noun incorporation? Lingua, 119.2, 148-165.

Benveniste, E. (1966). Convergences typologiques. L'Homme, 6.2, 5-12.

Bickel, B., \& Nichols, J. (2007). Inflectional morphology. In T. Shopen (Ed.), Language typology and syntactic description (p. 169 - 240). Cambridge: Cambridge University Press.

Creissels, D., \& Sambou, P. (manuscript). Le mandingue du kaabu, ou mandinka (mandinkakáno),.

DeLancey, S. (1981). The category of direction in Tibeto-Burman. Linguistics of the Tibeto-Burman Area, 6.1, 83-101.

Fortescue, M., Jacobson, S., \& Kaplan, L. (2010). Comparative Eskimo Dictionary, with Aleut cognates. Fairbanks: Alaska Native Language Center.

Garrett, A. (2004). The evolution of algic verbal stem structure: New evidence from yurok. In M. Ettlinger, F. Nicholas, \& M. Park-Doob (Eds.), Proceedings of the Thirtieth Annual Meeting of the Berkeley Linguistics Society, February 13-16, 2004: Special Session on the Morphology of Native American Languages (pp. 46-60). Berkeley: Berkeley Linguistics Society. 
Gerdts, D. B. (1998). Incorporation. In A. Spencer, \& A. Zwicky (Eds.), The Handbook of Morphology. Oxford: Blackwell.

Gerdts, D. B. (2003). The morphosyntax of halkomelem lexical suffixes. International Journal of American Linguistics, 69.4, 345-356.

Gerdts, D. B., \& Hukari, T. E. (2008). Halkomelem denominal verb constructions. International Journal of American Linguistics, 74.4, 489-510.

Goddard, I. (1990). Primary and secondary stem derivation in algonquian. International Journal of American Linguistics, 56.4, 449-483.

Gong, X. (to appear). Personal agreement system of zbu rgyalrong (ngyaltsu variety). Transactions of the Philological Society, .

Haspelmath, M. (1993). The diachronic externalization of inflection. Linguistics, 31.2, 279-309.

Haugen, J. D. (2008). Morphology at the Interfaces. Reduplication and Noun Incorporation in Uto-Aztecan. Amsterdam: Benjamins.

Hildebrandt, K. A. (2007). Prosodic and grammatical domains in limbu. Himalayan Linguistics, 8, 1-34.

Huang, B. (2007). Lawurongyu yanjiu 拉塢戎語研究 (Study on the Lavrung language). Beijing: Minzu chubanshe.

Jacques, G. (2004). Phonologie et morphologie du japhug (Rgyalrong). Ph.D. thesis Université Paris VII - Denis Diderot.

Jacques, G. (2008). Jiarongyu yanjiu 嘉絨語研究 (Study on the Rgyalrong language). Beijing: Minzu chubanshe.

Jacques, G. (2010). The Inverse in Japhug Rgyalrong. Language and Linguistics, 11.1, 127-157.

Jacques, G. (2011). The structure of the tangut verb. Journal of Chinese Linguistics, 39.2, 419-441.

Jacques, G. (2012a). Agreement morphology: the case of rgyalrongic and kiranti. Language and Linguistics, 13.1, 83-116.

Jacques, G. (2012b). Argument demotion in japhug rgyalrong. In K. Haude, \& G. Authier (Eds.), Ergativity, Valency and Voice (pp. 199-226). Berlin: Mouton De Gruyter.

Lai, Y. (2012). Wobzi lavrung phonology.

Launey, M. (1980). Introduction à la langue et à la littérature aztèque, tome 1: grammaire. Paris: L'Harmattan. 
Matisoff, J. A. (1973). The grammar of Lahu. Berkeley: University of California Press.

Matisoff, J. A. (2003). Handbook of Proto-Tibeto-Burman volume 135. Berkeley and Los Angeles: University of California press.

Mattissen, J. (2003). Dependent-head synthesis in Nivkh: a contribution to a typology of polysynthesis. Amsterdam: Benjamins.

Mattissen, J. (2006). The ontology and diachrony of polysynthesis. In D. Wunderlich (Ed.), Advances in the Theory of the Lexicon (p. 287-354). Berlin, New York: Mouton de Gruyter.

Mithun, M. (1984). The evolution of noun incorporation. Language, 60.4, 847-894.

Mithun, M. (1986). On the nature of noun incorporation. Language, 62, 3238 .

Mithun, M. (2000). The reordering of morphemes. In S. Gildea (Ed.), Reconstructing grammar, Comparative linguistics and gramamticalization (pp. 231-258). Amsterdam: Benjamins.

Mithun, M. (2009). Polysynthesis in the arctic. In M.-A. Mahieu, \& N. Tersis (Eds.), Variations on Polysynthesis, The Eskaleut languages (pp. 3-18). Amsterdam: Benjamins.

Nichols, J. D., \& Nyholm, E. (1995). A Concise Dictionary of Minnesota Ojibwe. Minneapolis: University of Minnesota Press.

Post, M. (2009). The phonology and grammar of galo words: A case study in benign disunity. Studies in Language, 33.4, 934-974.

Sadock, J. M. (1980). Noun incorporation in greenlandic: A case of syntactic word-formation. Language, 5\%, 300-319.

Sadock, J. M. (1986). Some notes on noun incorporation. Language, 62, 1931.

Sapir, E. (1911). The problem of noun incorporation in american languages. American Anthropologist, 13, 250-82.

Schackow, D. (2008). Clause linkage in Puma (Kiranti). Master's thesis Universität Leipzig.

Schiering, R., Bickel, B., \& Hildebrandt., K. A. (2010). The prosodic word is not universal (but emergent). Journal of Linguistics, 46, 657-709.

Sun, J. T.-S. (2000). Parallelisms in the verb morphology of sidaba rgyalrong and lavrung in rgyalrongic. Language and Linguistics, 1.1, 161-190. 
Sun, J. T.-S. (2003). Caodeng rgyalrong. In G. Thurgood, \& R. LaPolla (Eds.), The Sino-Tibetan languages (pp. 490-502). London: Routledge.

Sun, J. T.-S. (2005). Jiarongyuzu yuyan de yin'gao: liangge ge'an yanjiu 嘉戎語組語言的音高：兩個個案研究 (on pitch in the rgyalrongic languages: Two case studies). Yuyan yanjiu 語言研究, 25.1, 50-59.

Sun, J. T.-S. (2006). Jiarongyu dongci de paisheng xingtai 嘉戎語動詞的 派生形態 (derivational morphology in the rgyalrong verb). Minzu yuwen 民族語文, 4.3, 3-14.

Sun, J. T.-S. (2007). Morphological causative formation in shangzhai horpa. Bulletin of Chinese Linguistics, 1.2, 207-227.

Sun, J. T.-S., \& Shidanluo (2002). Caodeng jiarongyu yu rentong dengdi xiangguan de yufa xianxiang 草登嘉戎語與「認同等第」相關的語法現 象 (empathy hierarchy in caodeng rgyalrong grammar). Language and Linguistics, 3.1, 79-99. 